\title{
CAN ECOLOGICAL RELATIONSHIPS BE GROWN INDOORS? A RE-STORYING OF PLANT-CHILD RELATIONS
}

by

Leah May Shoemaker, BPA, Athabasca University, 2016

\author{
An MRP \\ presented to Ryerson University \\ in partial fulfillment of the \\ requirements for the degree of \\ Master of Arts \\ in the Program of \\ Early Childhood Studies
}

Toronto, Ontario, Canada, 2019

(C) Leah May Shoemaker 2019 


\section{AUTHOR'S DECLARATION FOR ELECTRONIC SUBMISSION OF A MRP}

I hereby declare that I am the sole author of this MRP. This is a true copy of the MRP, including any required final revisions.

I authorize Ryerson University to lend this MRP to other institutions or individuals for the purpose of scholarly research

I further authorize Ryerson University to reproduce this MRP by photocopying or by other means, in total or in part, at the request of other institutions or individuals for the purpose of scholarly research.

I understand that my MRP may be made electronically available to the public. 


\begin{abstract}
Can ecological relationships be grown indoors? A re-storying of plant-child relations

Master of Arts, 2019

Leah May Shoemaker

Program of Early Childhood Studies, Ryerson University

This multispecies ethnography case study uses poststructural and posthuman frameworks to question developmental standards, classification, and anthropocentric thinking in early childhood education. This research re-stories the relationships between plants and eleven preschool children as they share an indoor play area. Situated in what is now known as settler colonial Toronto, this research suggests small scale ways to re-narrate nature-child relationships in an era of climate change. Using writing style and findings, the research uses feminist methods to question what is included as valuable knowledge within the field of early childhood education.
\end{abstract}




\section{ACKNOWLEDGEMENTS}

I would like thank the children, staff, families, and more-than-human others that contributed to this project. I am grateful for the time, space, and stories that you shared with me. I have learned so much from you.

I would like to thank my supervisors Dr. Susan Jagger and Dr. Nicole Land for your incredible support through this journey. Thank you for creativity, kindness, limited boundaries, and the privilege to explore these ideas. Words cannot do justice how thankful I am.

Thank you Dr. Aurelia Di Santo, my second reader, for engaging with this work and providing me insightful feedback.

I would also like to acknowledge that this project was done with the land now known as Toronto, which is in the "Dish with One Spoon Territory". This is a treaty between the Anishinaabe, Mississaugas, and Haudenosaunee that bound them to share the territory and protect the land. With this acknowledgment comes further responsibility and commitment to the history, present, and future of this land that I reside on as a settler. 


\section{TABLE OF CONTENTS}

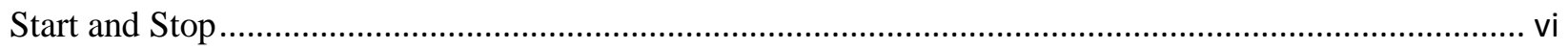

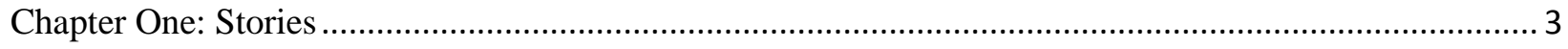

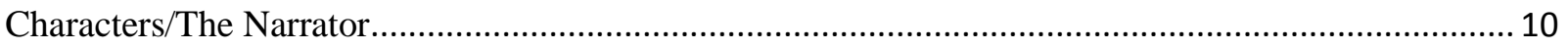

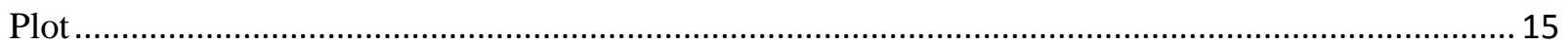

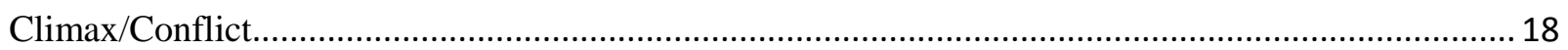

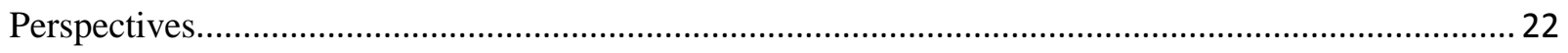

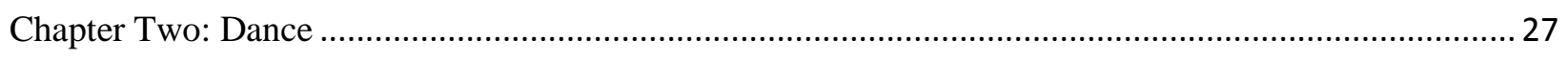

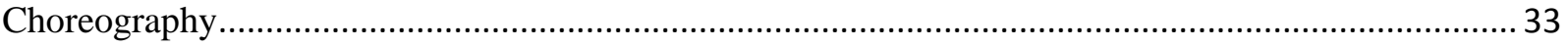

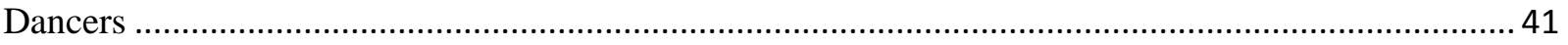

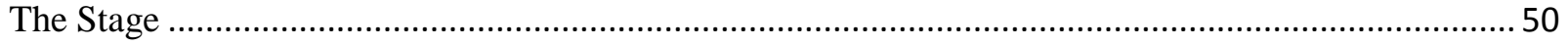

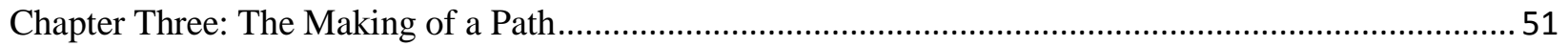

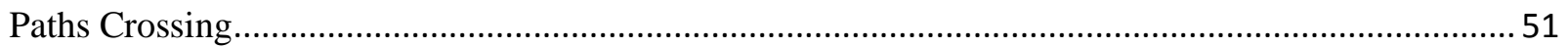

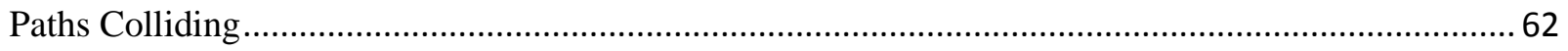

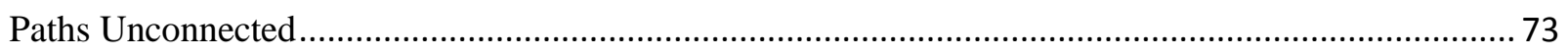

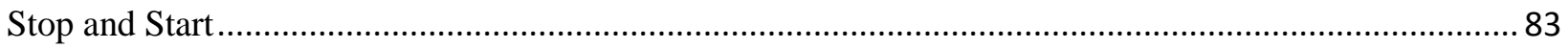

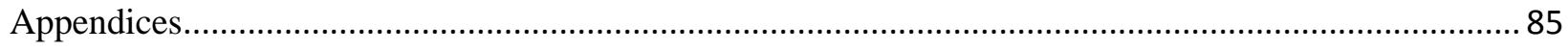

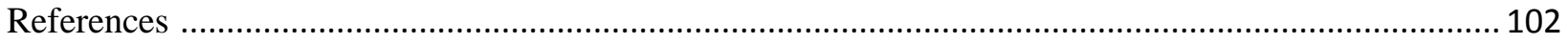




\section{LIST OF APPENDICES}

Appendix A - Manager Information and Invitation Letter

Appendix B - Educator Consent Agreement

Appendix C - Family Consent Agreement

Appendix D - Child Information Script

Appendix E - Child Assent Cards

98

Appendix F - Sharing Circle/Group Discussion Questions

99

Appendix G - Interview Guide

100

Appendix $\mathrm{H}$ - Interview During Narrative Guide

101 


\section{Start and Stop}

The writing of this paper does not conform to linear notions of time or structure. I recognize that this may make the paper more challenging for some to read, and perhaps this is my slightly vengeful way of pushing back against all the tirelessly academic papers I had to read to get me to this point in my writing. Both have their place. I urge those who have difficulty reading this format to sit with this challenge. This belief was strongly inspired by my first ever graduate level class presentation. For this assignment I facilitated a discussion on land and language: translating aboriginal cultures by Peter Cole (2002). Cole's piece was an incredibly difficult read for me as it broke away from what I understood about academic writing. With vulnerability and fear I approached my class of peers with an acknowledgement that I had difficulty understanding the poetic piece and I had considered asking for a different assignment but resisted. Instead of giving a traditional analysis for my assignment, I explained my emotional journey through the writing. This moment changed the trajectory of my thinking, writing, and researching. It was not solely through the words of Cole's piece that I gained new knowledge, but from moments of working through the challenge of trying to understand this writing that my insights were formed. It was within the context, the space between, where I found growth. Ironically, Cole's words on the page visualize this process in perfect metaphor as blank spaces separate the text. I reached out to Dr. Cole to tell him about my experience with his writing and with kindness he responded with the encouragement to,

"trust yourself your experiences your feelings and take some chances in your academic work" (P. Cole, email communication, Sept. 17, 2018).

Later he signed off with the reminder, 
“take courage challenge convention" (P. Cole, email communication, Oct. 1, 2018).

Throughout the writing in this current paper, a narrative style is used in conjunction with an academic voice. The narrative is set apart slightly and written in a lighter shade with a different style and size of font. This is to encourage the reader to pause and interact with the writing. The shade represents the need to solidify this narrative as important and valid within research, to not let it fade away. For these reasons the writing breaks formal APA format. The following research uses poststructural and posthuman theoretical frameworks to examine the ways that children and plants relate with each other in an indoor play area within early childhood education. My poststructural lens considers how stories and narratives shape and contribute to nature-child relationships and how each entity is represented in society. My posthuman perspective is used to (re)consider plants' agency within the plant-child relationships that transpired within this multispecies ethnographic case study. With this thinking I took plants into a childcare centre and explored how relationships can be seen through movement, gathering, and entanglement rather than as a human-dominated condition. In an era of climate change this research contributes to small scale, feminist methods by observing and learning from the already forming relationships between plant-child (Taylor, 2019). These methods are a push against the dominant narratives of human-centred evolution and as Taylor (2019) suggests, "leads us to tell different kinds of stories" (p. 2). 
Don't pick the flowers.

\section{Chapter One: Stories}

It was something that my mother taught me on my walks to school as young child, her calm eyes watching as I brushed the petals with my fingers. What I understood from this lesson was if I picked the flowers no one else could enjoy them, they would die, and only for my own enjoyment. In my late twenties I would rent a house that had a flourishing garden and I would move in to inherit the rich soil. That garden would change my life as I spent hours crawling between the rows of vegetables, cursing mosquitos and cherishing the dinners that I hadn't needed to shop for. In my final season with this garden before I moved across the country into an apartment as big as the plot we grew from I decided I wanted more flowers and less weeding. I carefully pushed sunflower seeds around the edges of the fence and sweet peas against the chain linked areas. Giant marigolds were planted in the green house, filling the humid space with their smell. I hurled wildflower seeds across plots within the garden in large squares and then in rows between vegetables. They burst into flower, wild, tangled and the bumblebees gathered. I sang 
love songs to them. I felt I could pick these flowers and I couldn't bare the idea of not filling my house with their smell and colour. I loved them so much, they were so beautiful. I picked them. I gathered mason jar after mason jar of their seeds and gifted them to others, still never coming close to collecting even a quarter of their yield. In the weeks coming I will ask someone to peek over the fence of the house I used to live in and tell me how these wild seeds are coming up. There were so many flowers it would not be possible to stop them from sprouting sporadically throughout the garden, perhaps for years to come. 


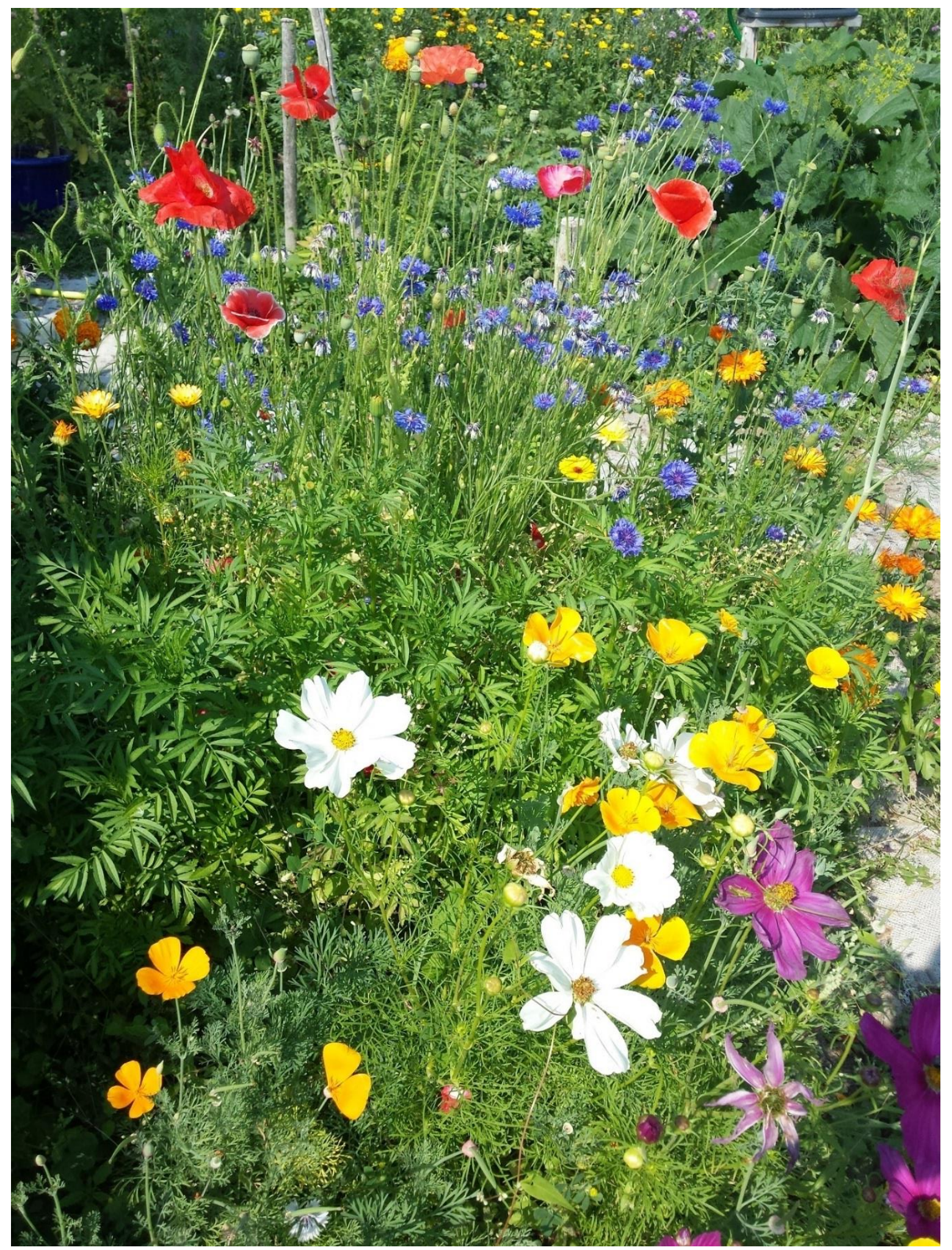


The definition of a story is yet another human defined word, bounded by context and our own imaginations. This theme of boundaries and human definitions is a reoccurring one that you will find in my stories. To me, everything is a story. The way information is passed, the movement of bodies, this research. I was a librarian in a past time and as an undergrad I studied communication the art of manipulation, I jokingly told people who asked which led me to worry about the way information influenced empathy. I continually visited questions on how technology and mass messaging affect the way people care about problems. Marshall McLuhan (2013), a Canadian philosopher I returned to regularly at that point in my studies, predicted that technology and the capacity of messaging could have a numbing effect on people. The stimulus of information being consumed would initiate this numbing as a protection response. When looking at non-profit industry and the rise of slacktivism, online advocacy with little impact, Kristofferson, White, and Peloza (2014) showed that tangible support for causes increased when people felt involved with a cause. It is a straightforward and human-centred concept; we feel more about the things that directly affect us.

Now, this winding path of my own story leads us to this current moment where I am typing. As I connect fingers to keyboard to document, the environmental change that is taking place on the planet is damaging both human and non-human species. Marginalized bodies are affected distinctly by the effects of climate change (Pulido, 2017; Nxumalo, 2018; Whyte, 2018). The human groups who impart damage most upon the environment, ironically are also those who are less directly affected by these impacts (Intergovernmental Panel on Climate Change, 2018). Why must empathy and care be so attached to the individual? Why have we separated and compartmentalized the universe into categories that stay within boundaries of human-based cognitive logic? What matters? What doesn't? How do we decide? 
Just as the species on the planet do not act in isolation, ecological issues are not isolated either and instead are linked to various social justice issues (Intergovernmental Panel on Climate Change, 2018). Indigenous techno scientist Kim TallBear believes that the worries colonial cultures have been feeling around the future of climate change are the realities that Indigenous communities have been feeling for over a century in what is known now as North America (University of Alberta, 2015). Potawatomi environmental scholar Kyle Whyte (2018) writes that narratives of the Anthropocene often premise this era as apocalyptic without recognizing the continuing persistence of Indigenous People who have been resilient against colonial practices distinctly connected to climate change. Whyte (2018) notes that many Indigenous People feel that the looming crisis that is discussed in colonial narratives has already been experienced by Indigenous communities, nations, and cultures. $\quad$ Tears streamed my cheeks as I sat in the backseat of my parent's car mourning the loss of a dear friend. We had driven by the house I had spent my fourth year of life in during a period when my parents were temporarily separated and my mother and siblings had moved from Los Angeles to Calgary. Now, a few years later my body felt what could only be described as heartache as we drove by the yard of the house I had spent that one year. The Alligator Tree, the one that had one strong branch that reached out and I could climb on top and ride with its bulging bark eyeballs, had been cut down. A best friend. Our grief. Holding various perspectives within the discussion, how are children included in stories 
of climate change? How is the more-than-human world represented in these stories? The narrative I wish to tell is about language and relationship and their interaction within the categories of nature and child. Robin Wall Kimmerer (2013) writes that "the stories we choose to shape our behaviours have adaptive consequences" (p. 30). As I process the narratives revolving around nature-child relationships I wonder how these stories can be retold in a way that includes the agency of nature's impact on these relations. The developmental discourses that dominate the field of early childhood education separate children as a distinct and universal category. In my experience as an ECE developmental discourse encouraged educators to manipulate class design in order to provide children opportunity to gain mastery over their environments. During this project I was interested in dismantling these hierarchies. Over a two-week period I observed plants and 11 preschool-aged children as they came together in an indoor play area. Through my writing and observations, I explored how these growing relationships inform how classrooms, cities, and society could be built together with the more-than-human world. Chapter one of this story guides you through the many questions that led me to this world-building. 


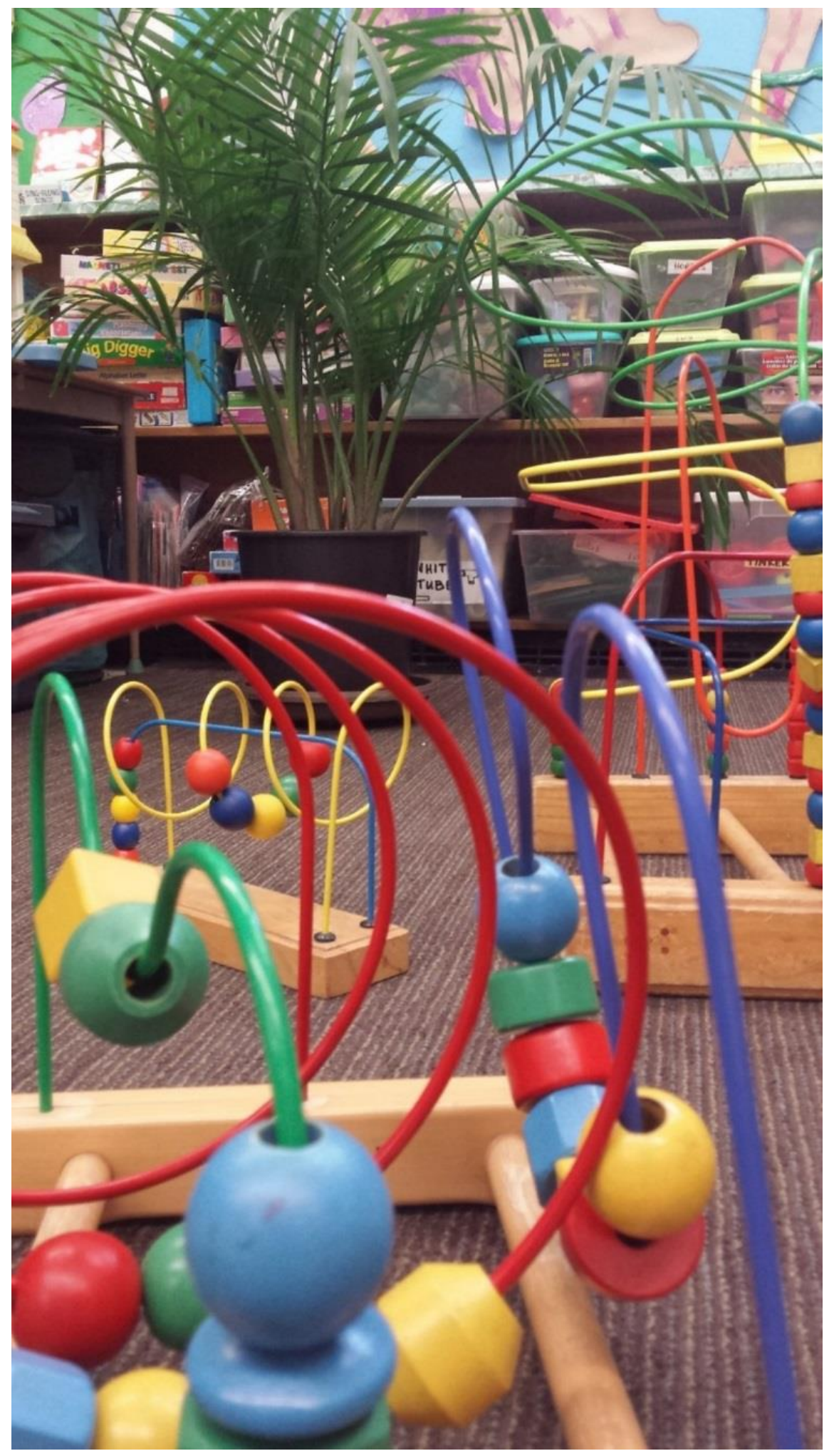




\section{Characters/The Narrator}

It is important that I am within my research because severing information from experiences dulls the complexity of knowledge. In my life, knowledge has never been formed without context, beliefs, or emotions. Constantly limiting the inclusion of these aspects in science creates an unnecessary barrier for different ways of knowing. As a researcher, I am represented through the writing of this project both in an academic tone and a narrative journey. Unlike many other modes of giving an account, a story can allow multiple meanings to travel alongside one another; it can hold open possibilities and interpretations and can refuse the kind of closure that prevents others from speaking or becoming. (van Dooren \& Rose, 2016, p. 85)

Through this process of writing the words take on a new material existence, one that is separate yet connected to the writer and the reader (Wolfe, 2010). My research is from the perspective of a white settler, however as I work through my thinking I cannot help but notice the similarities and parallels between the Euro-centric positioning of the academic frameworks I use in my

research and some aspects of Indigenous Knowledges. How do I work with posthuman frameworks without appropriating Indigenous Knowledge? It was a question I would ask several times without finding an answer that was clear or satisfying. For my entire life I would be taught by educators who looked like me, who spoke my language, who shared my culture. I would always feel safe and I would always feel comfortable if I allowed myself to sit there. 
In what is currently known as Canada, the Indian Act, which is still in place today amid ongoing settler colonialism, has contributed to Indigenous knowledges and traditions being devalued in society. Historically Canada used this Act to force Indigenous People to renounce their Indian status to obtain higher education. It was used to legally stop cultural practices from taking place and forced Indigenous children to attend residential schools where the aim was to remove their culture (Joseph, 2018). The very university that I am associated with is named after Egerton Ryerson, honouring the person who was key in developing residential schools, one of the greatest shames of this country. $\quad$ Yet this is not enough to change the name of the establishment. Yet I am still enrolled. "Why would you go to school there?" my friend would ask as I informed them of the person Ryerson University honoured through the legacy of this name. I promised myself that I would not attend convocation, I would not buy merchandise with this name on it, I would not hang my certificate bearing this name on my future office wall. But what does this achieve? This history continues to affect how Indigenous Knowledge is privileged within academic fields from early care to post-secondary. As I connect with the theoretical frameworks that attempt to blur the boundaries of universal categories and species, Kim TallBear (2011) notes that Indigenous standpoints must be recognized. I am looking at relationships between species, something that Indigenous traditions have long been understanding. This traditional knowledge on relationships has not been upheld in Western academia with the sophistication deserved, as distinct and without need for Euro-centric justification due to the history and ongoing aspects of colonization. I wish to share these parallels 
where they have presented themselves to me with an understanding that they have always been essential and original to stories of relationship with the more-than-human-world. TallBear notes that the relations between land and Indigenous People are distinctly entwined and these rights cannot be separated (University of Alberta, 2015). My writing is not an attempt to understand Indigenous People, something that research has notoriously abused. Instead, this is a pursuit of reconciling settler colonialism by recognizing the connections between humans and the morethan-human-world and the genocide that continues to take place within these relationships. In navigating my own struggle against appropriating Indigenous Knowledge within my theoretical framework, I hold this purpose forefront.

Systems theorist Luhmann (as cited in Wolfe, 2010) states "humans cannot communicate; not even their brains can communicate; not even their conscious minds can communicate. Only communication can communicate" (p. 19). With this idea my understanding of knowledge is expanded to consider how the method of writing has agency. van Dooren and Rose (2016) write on this, stating that "telling stories has consequences, one of which is that we will inevitably be drawn into new connections and, with them, new accountabilities and obligations" (p. 89). The meaning-making within the text is a construction of both what is and what is possible (Wolfe, 2010). Nothing is static and the stories inked onto page are a way of sharing and becoming something new (van Dooren \& Rose, 2016). The narrative within this writing engages with the situated context of myself as a researcher by dancing with and against linear notions of time. Through my writing I present my privilege, positioning, and human-centred default thinking. Through stories a more emotional connection can be made to theory, to free philosophy into something experiential as opposed to solely cognitive. The concept of ethos describes how characteristics and practices make up categories and is explored by van Dooren and Rose (2016). 
This practice and the pursuit of storying the engagements within and between ethos takes an understanding of self and other (van Dooren \& Rose, 2016). This narrative storying in the research provides opportunity to explore this relationship of self and other for all those engaged, to blur the lines where these categories meet. Through these narratives I also show that I am not an objective researcher. I do not set my values and experiences down in this project, tuck them away and attempt to diminish their influence. Instead let me share my self as a part of the story. Construction was taking place on the land that this learning centre was situated on, blocking us from visiting the outdoor classroom that had been designated for this centre. Instead a little piece of forested space about half a kilometre from the centre was offered to us to use as a substitute by one of the residents until construction was completed. Everyday the class of two and half to five-year olds would pack our snacks and water and I would bring my first aid kit, phone, and bear spray with us as we trekked across the open field to the new space. If you couldn't hear my voice, you were too far away was the guideline used for our adventures. We would spend the day in the forest discussing the baby eagles we watched grow, learning of the importance of leaving the wild asparagus to seed, tasting alfalfa, and climbing trees. 
Fast forward to Toronto, the children have been given permission to drop the walking rope they hang on to when they are venturing outside of the playground. There is a tiny patch of grass with dandelions sprouting across it. On request I create an invisible but understood barrier with my body between the green space and the road as the children stuff their pockets with the yellow flowers.

Although limited studies explore children's perceptions of nature and what it means to them (Adams \& Savahl, 2017), research continues to show that experiences with nature positively affect children (Chawla, 2007). These experiences may also have a lasting effect on the ecological behaviours of adults (Rice \& Torquati, 2013). Chawla (2007) found that experiences in nature as a child were aspects of leading conservationist's memories. Wells and Lekies (2006) also found positive environmental attitudes in adults correlating to their experiences in both wild and domestic nature. Positive attitudes were influenced more by wild experiences with nature which included activities such as hiking and camping. Experiences with domestic nature in childhood included caring and growing plants and had less correlation to positive environmental attitudes (Wells \& Lekies, 2006). Soga et al. (2016) found that both indirect and direct experiences with nature positively correlate to children's affective attitudes towards nature. Within research, play is continually associated with children's experiences in nature and at times children have shown to speak about their relationship with nature as a friendship (Hordyk, Dulude, \& Shem, 2015; Kalvaitis \& Monhardt, 2012). The importance that experiences in nature have in childhood have motivated many early childhood education 
preservice curricula to include a mandatory course on outdoor play. However, the language used within the nature-child narrative is more complicated than typical effect and benefit stories would assume. Within these relationships there is an element of power that is often unexplored to preserve a veil of innocence.

In environmental education, Taylor (2017) notes that stewardship narratives predominantly focus humans as being both the destructor and the saviour of the planet. This universal and simple understanding of humans sets all people to be equally responsible for the outcomes of environmental destruction (Taylor, 2017) despite research showing that different cultures impact climate change unevenly (Intergovernmental Panel on Climate Change, 2018). Neoliberal discourse on childhood situates this period of life within a normative binary of child/adult with adult being the full/developed/normal fixture of human species (Heydon \& Davies, 2019). In such discussion children are viewed as potential adults. Within environmental stewardship discourse this trope is upheld and children are seen as the future protectors of the planet (Taylor, 2017) combing both saviourism and neoliberal human-capital stories.

\section{Plot}

What is nature? This is the question that peaked this research project for me. Before I was even introduced to posthuman theorizing of scholars such as Fikile Nxumalo, Veronica PaciniKetchabaw, Affrica Taylor, Natasha Myers, and Anna Tsing who inspired me to think of nature's agency, I was using poststructuralism to explore language. The term nature is conceived from Latin origins relating to being born (Schinz, 1929; Kharkhordin, 2001). This original state connected to the natural being is a concept associated with innocence. Currently in capitalist, neoliberal society the concept of ecological nature is distinctly separated from humans and categorized into its own definition. The less human-touched a space is the more natural it can be considered. In a study with 11-16-year-old children, von Benzon (2018) found that these young 
people did not associate their urban landscapes as being natural. Instead, the descriptions of nature from these participants described it as being "“pure' and something entirely separate from human intervention" (von Benzon, 2018, p.82). Domesticated animals or plants put in pots were no longer considered natural due to the human interference.

"Where is nature?" I asked a child I was doing art with. "Far away," was the response. I looked outside to the Toronto-based playground at the trees just outside of the fenceline. Taking on aspects of JeanJacques Rousseau (1896/2003), a philosopher who is deeply engrained within the ethos of childhood studies, a child's own development is tainted by the destructive nature of society. According to Rousseau, better yet is to allow children to unfold in their natural state, uninfluenced by the evils of society.

"Can you put this baby in my tummy?" her voice asked me, holding a doll towards me while simultaneously pulling her shirt away from her body. "Babies grow in a body part called the uterus and they are not actually babies yet. They are fetuses until they are born," I said as I tucked the doll up under her shirt. I listened to the stories of people from the country I was born in as their rights were taken away due to the simple fact that they had been born with a uterus. I was instantly aware of the language that was being presented to children that enforced these laws. Pregnancy, an aspect that is inherently connected to early 


\section{childhood, was often deemed too taboo to speak of using basic}

\section{anatomy.}

The natural world also holds an aspect of innocence within ideologies, again in danger of human corruption. The most pristine of these innocent spaces given way to is the notion of wildnature, least touched by humanity (Taylor, 2017). However, even spaces considered wild inherit complicated legacies (Newberry, 2012). Both nature and children are overlaid with narratives of innocence and the relationship between these two categories is often discussed in such a way. Children's experiences in nature are considered innocent, genderless, and are romanticised (Nelson, 2019; Shillington \& Murnaghan, 2016). This relationship between nature and child is also seen within the binary of the normative child. In society the white, able-bodied, typically developed colonial child is considered to have the most valuable experience in nature (von Benzon, 2018; Nxumalo \& ross, 2019). These binaries leave little room for the intersecting contexts that may affect the understandings of both nature and childhood. Adams and Savahl (2017) discuss how racism, war, and poverty all can contribute to what is experienced and defined as a childhood and what is experienced and defined as nature. The language and narratives around nature, child, and the relationship between are always present and manifest in different ways. However, the relationships are not innocent. In Canada, the history of colonization and the continued pursuit of land reclamation for Indigenous People is a legacy that children contribute to and inherit (Taylor, 2019; Nxumalo, 2019). The narratives around climate change and the intersecting social responses from war and human migration entangle children. Shillington and Murnaghan (2016) show that these ideologies that idolize the innocent child in wilderness can be found in movements that promote children's connection to nature. These authors question how urban children are represented politically in spaces when their relationships 
with non-human life are seen as less valuable. For example, a children's playground may be designed based on natural aspects that would more closely match the concept of "wild" nature. These designs do not consider how children in the city may connect and relate with their environment as these "wild" spaces are not accessible.

Spiralling through post-structural questions about nature led me to Baudrillard's (1988) theory of a simulacrum. The simulacrum, or the simulation, is a copy which does not necessarily have or need a true original. When exploring that language of nature this space is seen in its truest form as being untouched by humans. This leaves the notion of nature as a fallacy however as humans would at the very least need to see it to define it, therefore contaminating the definition. The concept of wild nature can not actually be perceived by humans within this definition. Nature in this form is simply a copy created by society without a true or known original. This simulation is unstable, where does it begin and end? At what degree of human contact is nature no longer nature? When the first road runs through the forest? The house? The city? When our stories attempt to clearly define nature as separate from humanity based off a fictional original, it allows for the ethics of relationship to be ignored.

\section{Climax/Conflict}

My questions expanded outwards and then fell back in, as if breathing with me, pushing further and further away with each new aspect of information. Trying to organize these thoughts, to ground my thinking, to not lose myself in philosophy, what was I wondering? I often got lost in ideas as they became increasingly rhizomatic. I found it difficult to pull them back into an arrangement that would 
nature-child, I wondered how these stories fit within early childhood education, specifically in the city. Moving from a town of 3000 people to a city of almost three million had me questioning deficit thinking when it came to nature-child. How is the wind blowing between skyscrapers and playing with a child's hair being noticed? The grass growing between the sidewalk crack, pushed up from the dirt that supports the concrete? What about the tiny ant gathering crumbs around the lunch table in a preschool room? In an urban centre the simulation of wild nature is less accessible to provide within early childhood education. The playground is generally the only outdoor space children in these programs will experience daily. Rice and Torquati (2013) found higher income and education of families correlated to enrolling children in centres with playgrounds that were more naturally developed. In Canada over $80 \%$ of the population lives in cities (Government of Canada, 2014). As cities become denser and the cost of travelling to more naturally defined spaces increases, these environments are held as a privilege to families who can afford the cost and time to experience them.

The early childhood education classroom is regulated by different provincial and municipal governments and children spend more time in classrooms than any indoor environment other than their home (Mendell \& Heath, 2005). As regulations increase with little change to wages and support for educators, relationships of all kinds are diminished and replaced with a record of documented and quality learning that is taking place in the classroom. Dahlberg and Moss (2018) note that the discourse of quality early learning places adults as gatekeepers who measure how well children fit into the norm. In this model the trajectory of development is pre-determined by those in power and the meaning-making that takes place within context does not fit within the universal standard (Dahlberg \& Moss, 2018). There can be nothing new with 
set standards. The same story is repeated as all children are manipulated to fit into boxes that society uses to measure success. This idea of success has left many people, species, and materials on the sidelines. Educators are exemplified as technicians (Dahlberg \& Moss, 2018) and the discomfort that takes place in the space of not knowing the answer is not celebrated within a developmental framework. I believed so deeply in early childhood education when I switched careers to enter the field. I accepted that I would be returning to school to get certified and minimizing my wage substantially even after certification. It was worth it for doing work that was so important I thought. Living paycheque to paycheque, working 10-hour days without breaks, and feeling like I had to justify my work in language that showed the financial benefit to the economy rather than the care I showed for children and families took its toll however. I felt broken, I was broken. Society did not care about this role, government did not care about this role. I would enter grad school with this feeling, surrounded by classmates who felt similarly. We all questioned how we could make a difference.

Blaise, Hamm, and Iorio (2017) write that observation requirements in early childhood education are based on whether a child does or does not demonstrate specific skills which are set and determined to be important by educators and adults. "As detached and scientific observers, 
early childhood teachers are paying attention to individual children, assessing them through prefabricated sets of universal standards and benchmarks, and comparing this child with that child" (Blaise, Hamm, \& Iorio, 2017, p. 33). The developmental standards of ECE will always create a child who is deficit based on their inability to fit into the norm. Erica Burman (1994) discusses how the early role of developmental psychology contributed to classifying social inadequacies and controlling and regulating them. The knowledge children should be learning is pre-defined and is based on a hierarchy of power. The development model used in ECE is designed and implemented by a society which is currently contributing to significant violence against the more-than-human world. This model creates a limited scope of "normal" and leaves little room for context to explore the emerging, complicated, and entangled relationships that form between child and the world that they encounter. This model does not leave room for climate change, reconciliation, poverty, racism and the never-ending list of components that would contribute to people not fitting within a universal checklist of abilities.

Relationships between children and more-than-human others cannot be measured and quantified, resisting the limits of developmental standards.. Within a developmental system control, management, sanitation and safety have increased value. Educators are required to bleach natural materials such as pinecones and bark before bringing them into the classroom, ensure puddles do not breach size requirements, and keep climbing apparatuses dry. In the early childhood education room both children and the more-than-human world need to be controlled to be predictable so they fit within the context of normal development. As an educator myself, my critique of this power and need for control is distinctly placed upon developmental standards as a system of measurement, not individual educators. In developmental sciences the categories of child-nature are separate, distinct, and humanist. 
innocence within childhood is one that interrupts the ability to see the ECE classroom as a political landscape with people (children) who contribute to society. Day Beihler and Simon (2011) discuss how indoor spaces should not be ignored within environmental discussions as they provide context and representation of power and information present within societies. What are the stories being told about nature within childcare? Humans are separate and nature can be controlled either positively or negatively by our species. This is the Anthropocene. Just as our language maintains a binary between child and nature, indoor walls create a binary between the human world and the more-than-human world. My exploration blurs these boundaries by questioning what it means to share an indoor play space with plants in a preschool room.

\section{Perspectives}

The use and power of language is highlighted through my research and recognized for its inherently human-centred quality. Specifically, questioning the terms nature/child led me to this study. In what ways do our understanding of these concepts affect the way relations transpire? Poststructuralism questions the categories of normal and other that are formed through language binaries (Peters \& Burbules, 2004). In blurring the boundaries of binaries I notice that the semantic understanding of the very words used to categorize aspects of the more-than-human world affect the attributes of relationships. These categories however are not present in all cultures and are instead a Euro-centric concept. Indigenous knowledges already promote the blurring of these categories and the appreciation of the relationships that form between (Sundberg, 2014). Deloria (2001), in writing about Indigenous knowledge and traditions being understood through the concept of metaphysics, asserts that "the best description of Indian metaphysics was the realization that the world, and all its possible experiences, constituted a social reality, a fabric of life in which everything had the possibility of intimate knowing 
relationships because, ultimately, everything was related" (p. 2). Everything is about relationship. This study specifically identifies and questions the power structures of the early childhood education room and how these persist within children's relationships with the more-than-human-world.

The poststructural framework that I work with questions the singularity of truth that is revealed through empirical thinking and instead sinks into the complexity that is present from exploring the culture of a single classroom in a single early learning centre. In this study the language that constructs the dominant ideologies (Leavy, 2017) of the terms 'nature' and 'child' are examined to consider what is represented as valuable knowledge. Poststructuralism provides an opening for the examination of the way that power contributes to the construction of discourse (Cherryholmes, 1988). In the space of education, power is inserted into the categories of child and nature through the boundaries of what is considered valuable knowledge. The field of early learning continues to privilege developmental standards which define what is worth knowing and what is not based on the concept of a universal child and narratives of quality which assume "mastery, linearity and predictability, [and] objectivity" (Dahlberg \& Moss, 2018).

'Almost there!' said the note next to my letter grade telling me my informal standing. It was lower than the rest of my classes, but I didn't mind because I was so thrilled about the content and was finding space to experiment with ideas. I laughed when I read the comment as I thought about how I had gained more understanding from this class than so many others, despite the contrast in my GPA. The joy 
that materialized from interacting with the readings was something I

took with me in my everyday life, a life that seemed worlds away from academia. I was not looking to prove that I had reached a destination but regardless was somehow still attaching worth to this alphabetized standard. Poststructural thinking deconstructs these

notions of how a child should relate to the more-than-human world based on human-constructed definitions of nature. Deconstructing the meaning of these terms affects the physical structures (Cherryholmes, 1988). When the binaries that society has created to separate the human-centered world and the more-than-human world are disrupted, how can relationships be considered without the confines of human definitions? Heidegger's philosophy of technology shows the way that meaning frames all entities into matters of potential human resources (as cited in Burbules \& Peters, 2004). In Robin Wall Kimmerer's (2013) Potawatomi culture, and many Indigenous cultures, the land is seen as holding gifts that come "to you through no action of your own, free, having moved toward you without your beckoning. It is not a reward; you cannot earn it, or call it to you, or even deserve it" (p. 24). Kimmerer (2013) goes on to explain that in this language an ongoing relationship is formed with the land which continues a cycle of giving. In this research I explored how moving into observations with perceptions of nature-child connection rather than distinction troubled what I took note of. The stories that I held poured into my observations and into what I valued in these relationships.

In colonial narratives nature at its most extreme is seen only within a discourse of value based on the possibility of consumption (Burbules \& Peters, 2004). This study takes this concept which is highly prevalent in current context and combines a posthuman framework to question 
the human-centred thinking of the nature/human relationship. The politics of poststructuralism allows for posthuman thinking to examine the ontology of the space between language and being, a space that is encompassed by the act of becoming (Braidotti, 2018). As I move through this chapter the becoming is happening. In this research children aged two and half to three years old chose their own pseudonyms. Eleven children: Blue, Bulldozer, Cleah, Gooey, Green, Happy, Lily, Raya, Ronis, Unicorn, and YES shared the indoor space of a childcare room with plants: Small Succulents, Areca Palm, Gerber Daisy, Dahlia, Burro's Tail, Alyssums, Lemon Tree, Spearmint, Coriander, Osmin Basil, Strawberry Plant, Echeveria Succulent, Money Tree, Fern, Stromanthe Triostar, and Living Stone. When writing about plant participants I have

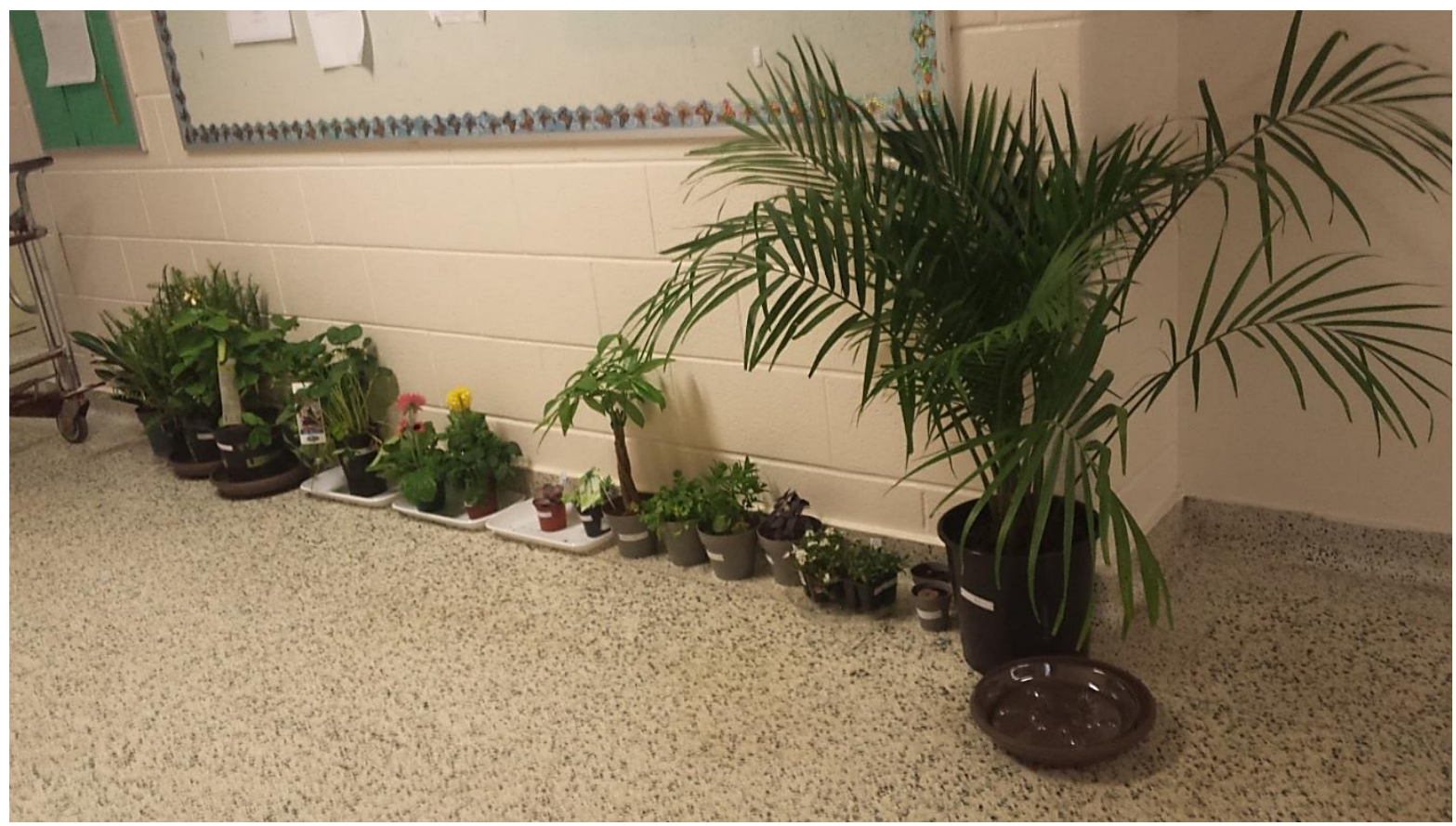

capitalized their names and removed the and it from the singular nouns. I have given them the pronouns they/them/their. This has been inspired by the writing of Robin Wall Kimmerer (2013) who discusses the way that the English language objectifies non-humans. It feels 
articles. The Strawberry Plant. Then I take them out again. Strawberry Plant. As I write and read, it becomes more comfortable. My memories of the plants shift and I feel my connection deepen. I miss the plants. I miss the children. Chapter two moves away from the narratives that grounded this study and explores the dance that transpired through the design of the research, the space in between context. 


\section{Chapter Two: Dance}

The plastic hula hoop vibrates slightly as my fingers wrap

around, tighten, and push the circle in the opposite direction. The hoop calls my other hand into the space that it now encompasses.

My hand grabs the outside edge and pulls the hoop up and over my body, I pull myself to the balls of my feet as I reach upwards to work with the momentum of the hula hoop. Dancers reach an instant of flow when they are completely present in the moment, no longer thinking about their next move but instead reacting to their partner, in my instance a piece of plastic. Our movement is entangled, meaning the outcome that occurs is completely dependent on each entity's relationship with the other. I can not ask how I move the hoop without also asking how the hoop moves me; the dance becomes through this relationship.

Chapter one of this study explored the way that nature-child narratives could be poststructurally questioned and how language and context contribute to relationships. That story led me to another one, a story of dance and movement. Through those narratives posthumanism manifested, a theory I first understood through my relationship with my hula hoop.

Posthumanism decentres human species from within the supremacy role that has been mitigated through Anthropocene (Braidotti, 2013). In a childcare setting, when outdoor experiences are limited to regulations and resources, how can the indoor classroom be a setting to experience 
common world relationships between plants and children which focus on interconnection rather than separation? Taylor (2017) writes that the term common world insists on the pedagogical exploration of the relations between human and more-than-human worlds.

This means pushing past the disciplinary framing of pedagogy as an a priori exclusively human activity and remaining open to what it might mean to learn collectively with the more-than-human world rather than about it, acknowledging more-than-human agency and paying attention to the mutual affects of human-nonhuman relations. (Taylor, 2017, p. 1455)

Using poststructural deconstruction, the term human is viewed as a universal title that creates deficit discourses (Braidotti, 2018). Agency is expanded to include the interconnectedness of both human and the more-than-human-world, resisting objectivity to understand relations (Braidotti, 2013). I see this agency enacted through motion. Braidotti (2018) notes that all subjects are in the process of moving through what no longer is and what will come to be. This act of motion transcends the ability to preform/perform concrete definitions, standards, and generalizations and instead calls upon thinking that is playful in nature and can dance between time, space, and material. De Line (2016) writes that "constant flux is the first tenet of Indigenous science and is based on the principle that all matter is in movement and everything changes" (p. 7). This concept of movement was something I came to through particle science. However, again this thinking could have been provided through Indigenous perspectives and knowledge if these traditions had been given equal importance within my education.

"A well-tended garden, whether in a bucket or on board a space station, provides a stage for plants and people to perform their entangled powers" (Myers, 2017b, p. 297). This research questions the relationships that take place within a preschool room as I reimagined it as a garden. 
Including both human and more-than-human aspects guided me to think about the hierarchies and conditional power dynamics within these connections.

The hula hoop is spinning around my neck. I feel the rhythm as it hits each angle of my body and I wait to tip my head underneath, leaving the hoop to spin only on my shoulder. As I attempt to bring my head back up through the hole it hits my face. Again. I feel a tiny bruise forming and my body tenses in frustration. The emotion wells up inside of me with no form of release. I have practiced this move repeatedly. We are out of sync. Dominant Euro-understandings of species separate child and plant into distinct and universal definitions. Posthumanism asks that this study question the ethics of sharing space with plants in an early childhood classroom (Taylor, 2017). It requires reflection on interactions that are predominantly developmentally led by an expectation of human control, then troubles this understanding by asking why this is. How might this expand how we view social interactions, care, and design within an ECE setting? Posthumanism is used in this research to question the dominant and colonial narratives that are privileged within the classroom environment (Pacini-Ketchabaw \& Nxumalo, 2018). These privileged narratives are presented through universalized categories that organize children, plants, materials, and knowledge within a classroom. In theorising this research, posthumanism not only questions the relationship between child-plant, but I continue to draw parallels between the cultural representations of these categories. Both classifications, plant and child, are viewed without active citizenship within society. Both are romanticised and constructed as innocent. Both are viewed within a neoliberal system as something measurable for future product; plants as a 
resource for human existence and children as future adults capable of solving the world's problems. These parallels are drawn out from the ability to separate and other these categories from the normative adult human.

Hogarth and Fletcher (2018) write that the categorization systems that dominate today's societal thinking stem from the period of Enlightenment when "defining elements, events, people, and things was the intellectual vehicle for understanding their value and meaning" (p. 3). That which is easily categorized, measured, and understood is easier to control, manage, and organize. This stream of thought is still very prevalent in the early childhood education system through the privileging of developmental science. Rautio (2017) notes that categorization is used to exploit but also to "protect, befriend, work with and share lives with" (p. 95).

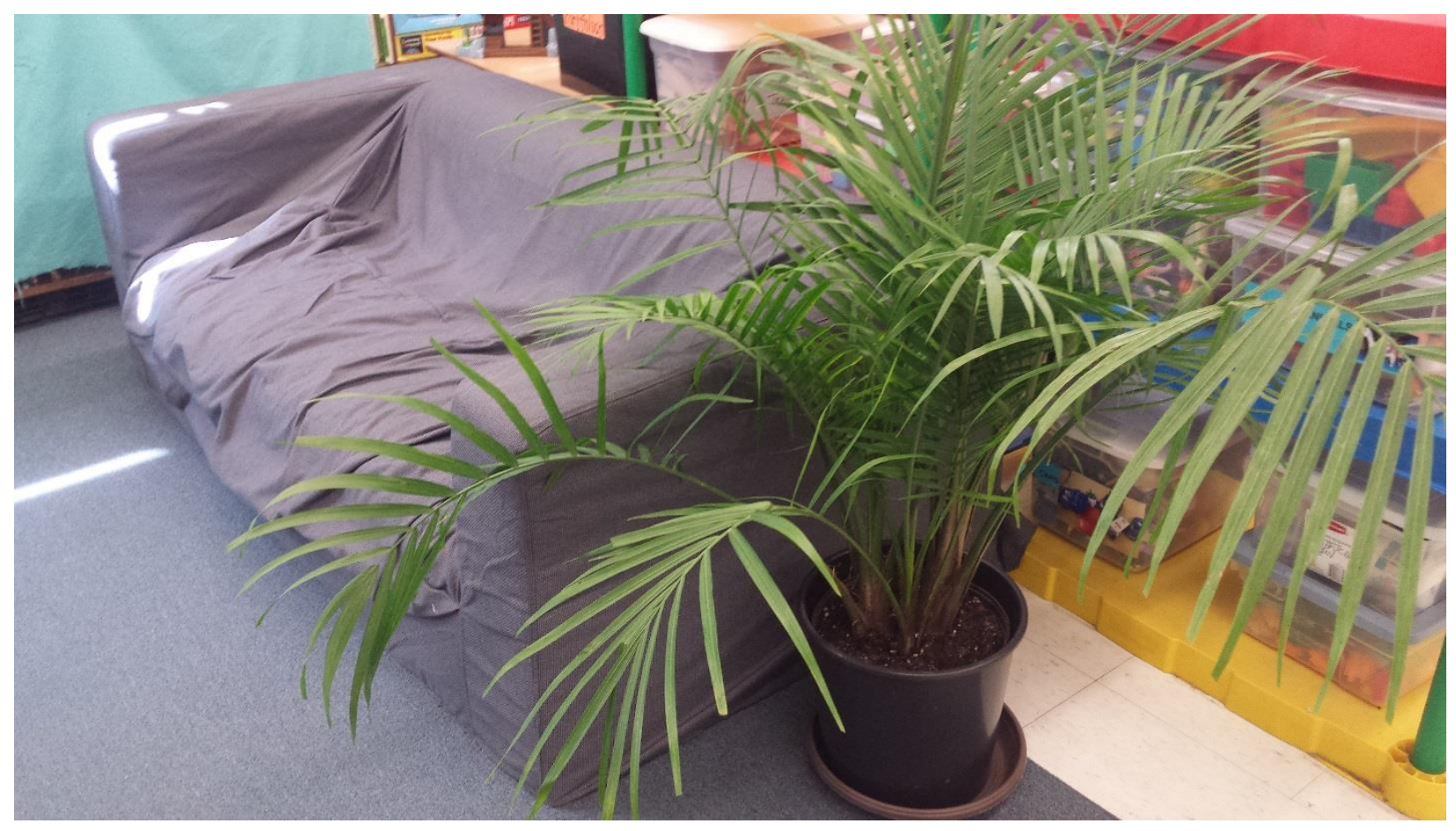

It is circle time and Areca Palm sits at the front of the group beside the couch where the story is being read. Lily is standing in the back 
of the group and Areca takes her gaze and calls Lily's body towards the front where Areca is sitting. Lily walks to Areca Palm. The expectation during this group routine is to be sitting and listening. Instead Lily is standing next to Areca, touching their leaves. "I want to touch it," she explains when she is reprimanded for not joining the group. After a moment of resistance, Lily complies and sits down on the carpet. Tsing (2015) notes that common world thinking can consider the ecological concept of assemblage, the coming together and influencing between communities, "staying alive—for every species—requires livable collaborations. Collaboration means working across difference, which leads to contamination. Without collaborations, we all die" (p. 31). In the current ecological climate the understanding of collaboration between and within categories of human and more-than-human seems increasingly urgent. In this research an ethical understanding of relational subjectivity is pursued (Tesar \& Arndt, 2018) to consider ecological behaviour as a matter of relationship rather than outcomes. Unicorn comes into the play space where the plants are all dispersed in the middle of the floor.

"Look there's some plants in the room," she says to me. It has been several days since the plants were first brought in to share the space. "What do you think?" I ask her. 
"Big one be real gentle," she tells me as she holds the tip of Areca Palm with her forefinger and thumb. She looks at me then tip toes out of the space. A window is open and a cool breeze flows through the space bringing in the smell of fresh rain. The flow of air moves Areca gently and a piece of art on the wall flutters in unison.

Osgood (2016) notes that posthumanism explores practices of material interaction that are not equally examined through the dominant developmental lenses of education.

The posthuman framework that I play with thinks with feminist scholars and requires engagement with the concept of plant voice and questions how the human bodies listen throughout the study.

I begin with the assumption that we are surrounded by forms of sentience that we have for the most part been trained to tune out and ignore; that we inhabit a more-than-human world that is always already sentient that this world full of beings, becomings, and processes of coming undone, is pullulating with sensing and sensitive forms of life and death that are attending and attuning, caught up in dances with and athwart one another, composing and decomposing in responsive, repulsive, and propulsive relation. (Myers, 2017a, p. 76)

The language of plants is not for humans to understand, but to approach with wilful unknowing in hopes to find new forms of questioning and listening (Myers, 2017a). To explore the concept of plant agency within human-plant relations observations, I needed to consider how plants call 
children into connection and vice versa, a question inspired by the work of Blaise, Hamm, and Iorio (2017).

\section{Choreography}

This study brought plants into an indoor play area of a preschool classroom with the understanding that these plants were a part of the space that could be touched, looked at, moved and interacted with by the children in the class. In my experience, plants within classrooms were often positioned as passive decoration to be viewed rather than touched or played with. The design of the project included a two-week volunteer period and two weeks of data collection. The research went into data collection with two broad questions: 1) how do young children and plants relate when they share an indoor play area and 2) how do plants trouble this play area?

The research site is organized. Shelving is filled with plastic boxes with various toys inside. Each box is labeled, many with a picture to indicate the toys which are inside. Each day several different tables are set up with toys on them and children can freely choose between their stations. The number of children that can play at each station is controlled by materials such as trays, chairs, or place mats. The children know the rules well enough that some of them monitor each other ensuring that the specific toys stay at the designated tables. The walls are covered in colourful art that children have done, often with a note that connects the art back to the developmental domain that was measured during the project. If 


\section{children's voices get too loud or their bodies too fast they are softly}

\section{and kindly reminded to be quiet and slow down. The class is safe,}

the class is in control. The dominant discourses that I critically notice in

early childhood education indoor play areas are organization, control, safety, sanitization, and a focus on human-centred relationships. Entering data collection I considered how plants could unsettle these routines of early childhood and why that would be something that the field of ECE would want to explore. Dominant discourses uphold ideas as being right or the only option and are therefore left unquestioned (Moss, Dahlberg, Olsson Mariett, \& Vanderbroeck, 2016). Using my theoretical frameworks to question developmental psychology in its role as the dominant discourse of early childhood expands and makes room for new questions. As I explored the relationships that formed within the walls of the classroom, I questioned how the presence of these plants created room to expand on what is upheld as the right way to do things within ECE.

Using a qualitative and multispecies ethnographic case study, the design collected rich data based on the experiences of both human and more-than-human (plant) participants. The methods of this study were difficult to define due to the problematic nature of ethnography which was designed to understand human culture. This study resists this aspect of ethnography and instead takes the tools of observing and listening and applies it to multiple species, then renarrates these using methods of van Dooren and Rose's (2016) lively storying. Hamilton and Taylor (2017) warn against fetishizing new research practices and multispecies ethnography risks falling into a trap of reinstating human/plant binaries. The term ethnography means “writing about groups of people” (Creswell, 2008, p. 472). Qualifying this study as ethnographic consciously engaged with the problematic aspects and history of this design. I resist thinking that uses ethnographic design to understand or define cultures. Doing so with this group of plant- 
children would reinforce the universal categories that support developmental standards and anthropocentric tendencies. Although the design does not fit perfectly within the category of ethnography, I resisted naming a new method for this research. Instead of building a new category, I blurred an existing one. I still engaged with the questions of practice on how observations would unfold, how to notice the voice of (multispecies) participants, and what space the researcher holds within place and time. I went into data collection without having answers to these questions. The design of this research was experimental. Rather than dissecting the species and compartmentalizing plants and children, this form of ethnography looked at the ways multiple species come together and relate within a common world (Pacini-Ketchabaw et al., 2016). These methods do not stray far from traditional tools which stress collective nature and diverge focus from individuals to groups (Angrosino, 2007). The method still used prolonged contact within specific context and used observations, listening, and questions to produce findings (O'Reilly, 2009). The challenge however, was the inevitable flux back into human-centric questioning and thinking (Pacini-Ketchabaw et al., 2016). To deny this tendency of the human-researcher negates the purpose and value of posthuman thinking. To acknowledge the human-led aspect of this research I present it as ethnographic but resist the tendencies that present it as human-centred.

The posthuman thinking that is used by scholars such as Affrica Taylor (2017) to resist the Anthropocene which places people as the centre of all problems and solutions, is drawn from the very tendency to slip into human-centric narrative. Rather than consistently pushing down this tendency I provide it honestly for analysis. However, it should be clear that I am not attempting to remove humans and specifically children from observations. To dismiss humans from being a distinct and agential force within the universe is a humanist notion. Specifically, 
within discussions of climate change, human destruction can not be ignored (Taylor, 2019). With this I recognize that I am not dismantling human agency, but instead noticing more-than-human agency. I acknowledge that these relationships take place regardless of my noticing. However, dancing through these relationships the very human act of noticing how plants have influence in the ways that movement, power, and knowledge assembles may bring different steps to the choreography. Taylor and Hamilton (2017) write that multispecies-ethnography still recognizes that fieldwork relies centrally on the human-researcher but believe that an openness in writing and a flexibility within the methods provides new possibility on what ethnography can encompass.

For those who want to break free of humanist conventions, we argue that it is acceptable — even desirable — to ask questions that may not be immediately answerable. It is also acceptable to be perplexed and humbled by this task. This discomfort helps us to reveal and to reflect upon the politics of knowledge and the limitations of existing method. It is how we reveal the faults and weaknesses of our normative research processes, knowledges and means of learning. (Hamilton \& Taylor, 2017, p. 24) Qualitative research aims to gain meaning from participants rather than use the researcher's lens as a guiding point to meaning-making (Creswell, 2014). Additionally, qualitative research paints a holistic picture (Creswell, 2014) as is such in the current research which explores the varying perspectives through different modes of communication. The design included observations, photos of plants, and provided child-participants an opportunity to take part in an art narrative process. During this narrative process children were asked if they would like to share stories about the plants using art. While children coloured they spoke with me about their drawings and their perceptions of the plants in the class. 
The design of this research situates itself within a single childcare room in a Toronto childcare centre. The design helped me as a researcher distinguish how I was going to move with and in the research. Through my writing I share the imperfect moments of being a human researcher. The classroom is empty of children after the first session of observing the plant-child relations. I sweep up a bit of dirt and foliage which had been spilled and take a moment to water each plant. I assumed this was an activity the children would all be wanting to do, I thought this would be the way they would show care. It was only after spotting me watering on one of the last days did any of them discuss watering the plants with me. case study design puts focus on the particular classroom as the single case and looks at the actions within this classroom rather than specific patterns (Creswell, 2008). Additionally, the case study does not approach the research with an overarching cultural theme to guide the design and instead explores the individual classroom in-depth (Creswell, 2008). Case studies are situated within a larger framework (Creswell, 2008), in this case the classroom situated within the field of early childhood education, but are often dismissed due to the lack of generalization towards a larger population (Lincoln \& Guba, 2009).

So convinced are many scientists that generalizations are the be-all and end-all of inquiry that they seriously question whether scientific activity aimed at something other than the establishment of generalizations is worth the effort. They assert that if one rejects the goal of achieving generalizations, all that can be left is knowledge of the particular - and they ask, 'What value could there be in knowing only the unique?' But this posture 
ignores the fact that we are not dealing with an either/or proposition; the alternatives include more than deciding between nomic generalizations, on the one hand, and unique, particularized knowledge, on the other. (Lincoln \& Guba, 2009, p. 27)

Rather than seek broad sweeping generalizations, Stake (2009) proposes that case studies provide naturalistic generalizations in which the user relates to findings due to experience. This then forms knowledge on ways of thinking about the world (Stake, 2009). In this study these concepts are used congruently with the ethnographic method to inquire into multispecies relationships.

Levine (2007) recognizes ethnographic research as an account situated in space and time. Riain (2009) states that ethnographic case studies seek to show how the link to personal histories of the researcher is tied to the larger structure of dynamics in both the society and the situated research. Narrative is used throughout this ethnographic design to question the relationship between self and theory. The culture represented within this data cannot nor should not be viewed as a representative of classrooms, children, or interspecies relationships universally. Our Grade 7 class sat in rows at our desks as a standardized test is passed out to the students. There is silence in the room as my classmates mark pencil to paper. I look at my paper and quickly fill in the multiple-choice bubbles without reading the answers, leaving my score to fate. This specific test would not affect my actual grade and I knew that. It was not designed to be a representation of me; it was a representation of the classroom, the school, the district, the 
province. $\quad$ Yet the individual study provides a political landscape placed within Canadian culture where discourses of society are reproduced and contributed to (Riain, 2009). The value of small-scale, qualitative research and its ability to reproduce meaning can be paralleled to discourse around children's participation as active citizens. Early childhood education classrooms have long been viewed as neutral spaces absent of sexuality, race, privilege, and oppression despite the presence of all these factors in the identities of children. This case study explores a moment not presented as a truth to generalize all other aspects of reality, but to be used to critically engage with actions and thoughts.

The research design rejects discourse on objectivity and instead aims to be transparent in the researcher's placement within the study. Ethnography recognizes the presence of the ethnographer within the research and the human nature and messiness that is present when collecting data (Riain, 2009). The posthuman perspective in this study aims to decentre the human within the traditionally human-focused ethnographic design. Pacini-Ketchabaw et al. (2016) recognize the challenge of attempting such decentring within the field of early childhood education which is dedicated to discourse on the individual child. As children generally hold a marginalized space within society, it is difficult not to champion this aspect of the research. However, this study responds with more complexity by requesting that these dynamics are viewed within a framework that recognizes both children and the more-than-human world contribute to these varying levels of power. When observations slip towards being humancentred, this is a representation of these power dynamics in action. Hamilton and Taylor (2017) notably state that

One of the great strengths and limitations of posthumanism is that it paradoxically both resists and embraces method. It encourages us to ask questions that are difficult to 
answer, research topics and issues that currently have few (or no) methods to bring into play. (p. 168)

I am sitting on a chair not quite in the middle of the room so I can see all the plants within the classroom. Today the children have set out the plants throughout the class, on toy tables, shelves, and play space floors. I start my observations each day by focusing on these plants because I soon recognized how quickly I am drawn into other aspects of the classroom.

"I brushed my teeth today, my breath was stinky but then I brushed my teeth." The little voice telling me this is standing close to my face and they open their mouth wide so I can view the setting of the story, their pink tongue and small teeth. I am instantly drawn in, smiling, laughing. I am charmed by this story and that this child would want to share it with me. I let go of my purpose, forget the plants, and discuss our morning together. I t take this statement with humour and humility and address the concern of human-centred observations by utilizing narrative tools. 


\section{Dancers}

Working with a multispecies ethnographic design meant looking at the concept of participants as inclusive of both plants and children. The act of purchasing plants and placing them in a childcare room required engagement with ethics regarding the plants as well as to the children. My basic understanding of plant care meant I needed to find plants that could live inside, rather than plants that may be native to this area, possibly erased from the space due to human activity. I also had to ensure they were not toxic, as per Toronto Public Health regulations. There were numerous questions relating to the plants that I spent limited time exploring. Bringing the plants into the classroom brings up questions of colonizing nature. Many of these plants would not survive the Toronto outdoor conditions, but were they moved from outdoor locations where they would have flourished more? Were they grown from seed? How
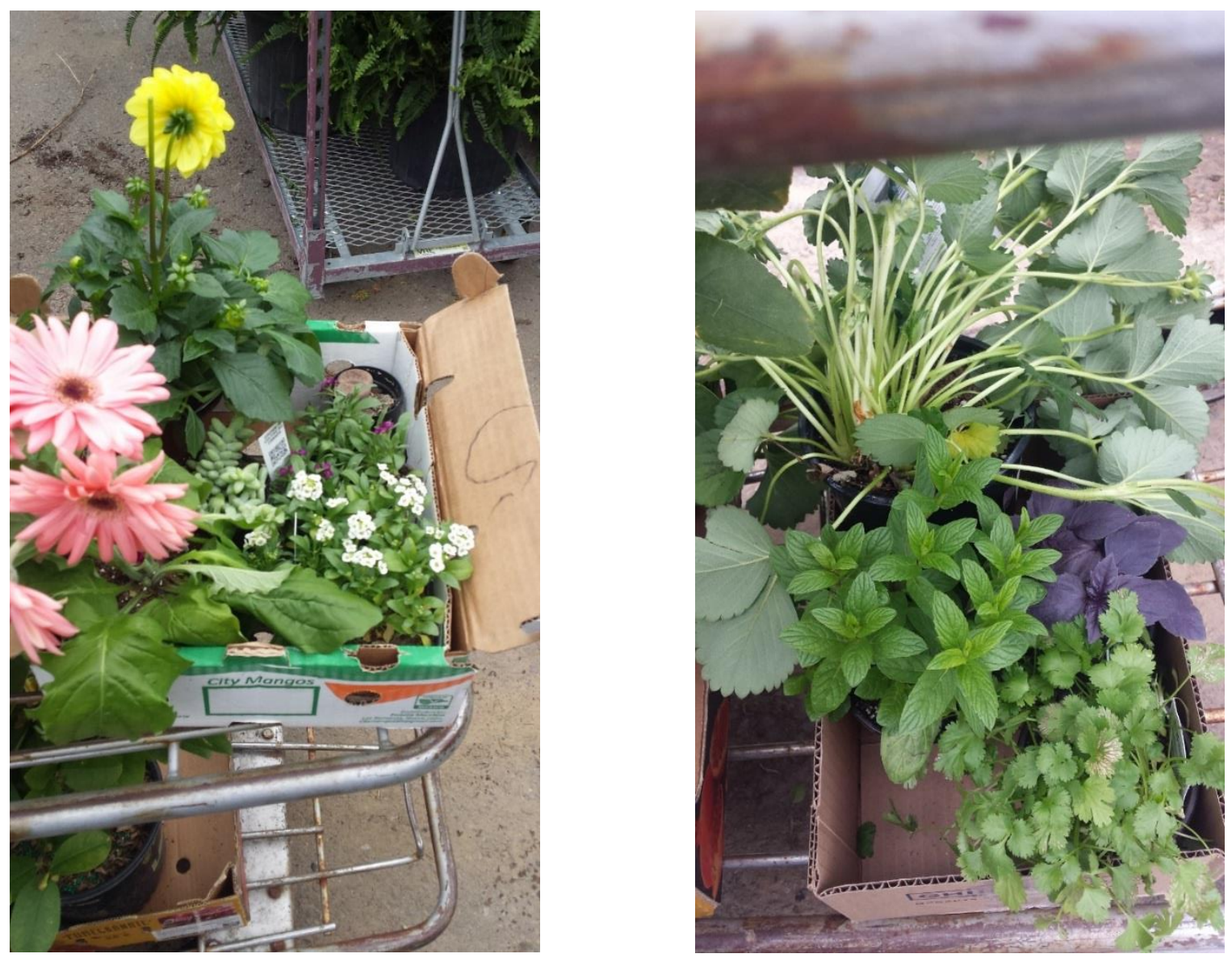
was purchasing these plants contributing to a violent, capitalist structure? Notably I avoided exploring these questions too deeply so I could justify purchasing the plants at the closest nursery because I did not have a car to transport them. The nursery let me borrow a cart to roll the plants over. Recruiting plants took on elements of convenience sampling (Leavy, 2017).

I can tell my research is affecting me personally. Walking home one day I could not resist buying a fuchsia plant from a corner grocer. The unique flowers spilled over the edge of the basket as I hung it from my ceiling beside my bed. Soon I noticed the dried leaves and shrivelling flowers were dropping at a rapid rate. I brought my face close to the plant and realized it needed more water than the rest of my indoor greenery. Tears welled in my eyes as I repeatedly whispered, "Please don't die, I'm sorry." I felt the selfishness and greed in my act of bringing this plant home with me. Unable to properly give this plant what it needed in my little apartment the beauty that it once held was withering. Plants constantly ask me to use will power, to take only what I need, to sacrifice desire.

Recruiting children used a combination of purposeful and convenience sampling (LewisBeck, Bryman, \& Futing Liao, 2004). The research is situated in the field of early childhood education and child-participants were purposefully sampled from within a preschool classroom. 
This method of sampling addresses the research questions in a way that could not be done without a purposeful sample and allows for a deeper understanding of the topic (Leavy, 2017). Selecting a sample of preschoolers in their classroom allowed the research to explore specifically how indoor plants can be incorporated in the field of early childhood education. The preschool classroom was selected through convenience sampling (Lewis-Beck et al., 2004). Educational spaces are not openly accessible to research and therefore a convenience sample is necessary. However, the available access to this sample exemplifies the power dynamic between researcher and participants as the study can capitalize on children's compulsory attendance in childcare as decided by their families (David, Edwards, \& Alldred, 2001). Children have limited participation in their decision to attend childcare. This highlights the importance of voluntary assent within the research. After family consent to choose to participate in the project was received, 11 children aged two-and-half to three years old chose to participate in data collection. During the research, children who did not have family consent or chose not to assent to data collection were still given the same opportunity as children-participants to relate with plants in the class and share art narratives about the plants. These moments were not included in the data.

Ethical review for research with plant-participants is non-existent, whereas approval from Ryerson University's Research Ethics Board was gained to do research with child-participants. When I explored my own ethical responsibility to the multiple species of participants, I found I often fell back on the human-centred notion of being a "conductor" of research and questioned how to minimize this. Rather than approaching the project as a human asserting power over both children and the more-than-human species by altering the environment, I shifted my perspective to ask what relations form when worlds combine as they do every day. How can this research share these relations? How are participant voices recognized? 
"How did sharing the space with plants make you feel?" I asked YES who was creating art about the plants while I asked her questions. She is deeply focused on the smooth movement of gel crayon to paper. Hearing my question she places her hand on the paper. Not noticing what she is telling me with this action I ask my question again. She moves her hand over her paper.

"Soft," she replies. She was telling me how the plant she was drawing physically feels. Language cannot be the only way to interpret knowledge, as it has its limits. This should not be misinterpreted as YES having limited knowledge. Children already experience the coming together of plants through gardens and indoor plants. These common worlds are a place to recognize the dynamics of power that are at play between all those involved (Pacini-Ketchabaw, Taylor, \& Blaise, 2016).

As the voice of child participants is considered in this study, so too is the notion of plant's voice. The article started to address the concept of photography consent with a tiger (Hamilton \& Taylor, 2017) when I noticed I rolled my eyes at myself. Was I really going to go down this path? Question consent in relation to plants, a concept some of my high school cohort could not grasp when considering people? With 


\section{all things uncomfortable this feeling was worth exploring to find out}

why it unsettled me. $\quad$ Myers (2017a) suggests that the feeling of

opposition that comes with the concept of plant voice and knowledge may be led by colonial perceptions of both land and body. Kimmerer (2013) notes that Western science has only just started to consider the concept of plant communication, something that Kimmerer's Indigenous elders had been observing long before. Kimmerer (2013) writes about pollen being carried by wind, interconnected root systems, and pheromones travelling from tree to tree within the frame of plant communication. Hamilton and Taylor (2017) argue that the entangled relationship that humans and the more-than-human world take-up is cause to include multispecies voice within research. Restriction criteria should not relate to the ability to fit within human behaviour. Children too have predominantly been lacking in research and their voices not listened to. "Almost all of Western science is reductionist in nature and seeks to force natural experience and knowledge into predetermined categories that ultimately fail to describe or explain anything" (Deloria, 2001, p.4). Pursuing different ways of listening speaks to a larger picture of values and what is worthy of being heard. What is possible if we listen deeper, what might we learn? This alone goes against developmental standards that negate early childhood. These dominant developmental standards are set by laying out what we already know and what we predict we should see rather than exploring new ways of listening.

The research project started with a two-week volunteer period where I spent time in the room getting to know the classroom, staff, and children. This period was offered not only to get to know the community but also as a gift of thanks in understanding that this project would bring change to classroom that might not always be comfortable. During this second week of the project the child assent process started. 
into my research project, right before starting the assent process. I came into the classroom and was sitting with a group of children saying my morning hellos as Lily stared at me sceptically.

"Are you the same Leah?" she asked me. As I listened to the hesitancy in her voice I realized my mistake. I had spent this time to bring comfort to my presence in the classroom. Now, I had troubled this by changing the way I looked drastically enough that this three-year-old questioned my identity within the class. She asked me several more times during the day whether I was the same Leah and I couldn't help but feel there was a slight tension in the way the children and I were interacting. Was this in my head? Were they more comfortable with my presence, I was less of a novelty, and therefore slightly standoffish? Or were they unsure who I was? In the field of research, child assent is recognized in various and contradicting ways, often relying on developmental standards and abilities (Oulton et al., 2016). Assent within this research project was voluntary and informed and based on a framework that distinguishes children as capable of participation. It was constructed with the belief that all children have the right to meaningfully participate in activities they are being recruited for (Oulton et al., 2016). 
"What do think about having plants in the classroom?" I ask Happy who is creating an art narrative for the research.

"It grows and it grows and it grows. You can record my voice," he tells me.

"I am recording your voice, I know," I respond. I had asked his permission before starting the art process, but Happy continuously came to me during observations to explore the voice recorder. He loved to listen back to this device.

"Please record my voice, please turn it on," he asks.

"It's already on. I'm going to listen to it later and write these notes.

See how I am writing what you are saying?"

Working on art beside him, Unicorn pipes in "For research!" she exclaims.

"And do research," Happy agrees.

The child assent process used the Child Information Script (Appendix D) to explain the project to children individually or in pairs. Children were encouraged to ask questions during this process before they were given the Child Assent Cards (Appendix E) to mark on their own. Children marked either the green happy face to participate or the orange frown if they do not wish to participate (S. Jagger, personal communication, 2019). Children did the same process to mark whether they assent to having their voice audio recorded. 
Assent was ongoing and reoccurring (David et al., 2001) and was distinctly referred to during different periods of the research such as before audio recording and during narrative creation. During the audio assent I pulled out the recorder I would be using for the project. Instantly Unicorn recoiled her body, her face scrunching. I pulled the recorder away from her as she whimpered slightly.

"This is the voice recorder, do you want me to show you how it works?" I asked her cautiously. She shook her head and I could see tears starting to form. I put it away quickly. "It looks like you don'† want me to use the voice recorder, that is okay," I reaffirmed. She marked the orange frown to show she did not assent to having her voice recorded and her body started to regain composure. Days later, during a process where child-participants were invited to use art as a story-telling method, I had the audio recorder on the table. As Unicorn sat down to do the art, her eyes fell to the recorder. "You told me you did not want me to record your voice before. Is it okay for me to record your voice now or no?" She nodded her head enthusiastically and I showed her how the recorder worked 
before asking her again if it was okay to record her voice. She again said it was okay and we continued through the art process.

A selection of plants were purchased and brought into the classroom after gaining ideas from children on how plants could share the room. Sitting in a circle I acknowledged that talking circles, a common practice in ECE, were a tradition learned from Indigenous People whose land we lived on. We started in a clockwise formation but quickly jumped to a child who was ready to share and then continued clockwise from there, passing a talking stick to acknowledge whose turn it was to speak. Children pointed out the shelves they would like to put the plants on and requested that I find "big" and "little" plants, purple, pink, and yellow plants. "Strawberries with leaves and corn," Happy requested, followed by the directions that the plants could share the floor space with us. Pineapple, apple, ice cream, and bubble gum plants were all requested. Many of the requests I could not fulfill but I found a range of sizes, filled the colour requests, found a strawberry plant with green berries and white flowers forming, and a lemon instead of an apple tree. As I walked in the door the first day the plants would be joining the class Cleah asked me right away where the bubble 
gum plant was. I showed her Stromanthe Triostar with their deep pink

\section{colouring and explained I could not find the plant that bubble gum}

was made from but found a plant that had leaves that reminded

\section{me of bubble gum.}

\section{The Stage}

The preschool classroom is an important agent within this research. The preschool classroom is a natural setting as defined by Leavy (2017) which in this case means that it is a common space that is part of children's regular routines. This setting allows the ethnographic methods to have a better understanding of the culture that takes place within the daily lives of the children. The classroom is politicized by both its structure and its function in its representation of colonial boundaries of Eurocentric knowledge capital. In an era of human-centred consumption and destruction, "perhaps one lesson we can learn is that it is time to stop designing for the Anthropocene; to stop locking ourselves into futures bound to these forces" (Myers, 2017b, p. 299). In my mind the classroom in this study was reimagined into a garden, a place where people navigate relationships with plants (Myers, 2019). The early childhood education room holds certain barriers, such as restrictions from Toronto Public Health, which shed light on planthuman relations. The classroom is not only considered a setting within this research, but also a participant in the research. When questioning the ways that indoor spaces represent human ability to control, manage, and organize environments, can these small landscapes hold relational opportunities to resist the Anthropocene? When we dance, will we recognize our partner's movement? 


\section{Chapter Three: The Making of a Path}

Incorporating and understanding common worlds asks that observations consider the democracy of the classroom and how this can include the more-than-human-world in decision making (Taylor \& Giugni, 2012). As my observations took place I started to notice the ways that paths were formed between plant-child and the way that movement within these paths entangled.

\section{A space for movement to pass through. Some paths}

overgrown, rugged, winding while others are distinct and clear. The paths between child-plant varied as the space between them was at times large, leaving room for both to spread out or seemingly never to touch at all. Other times these paths were narrow and complicated and needed movement that was tight and rigged and incorporated contact between plant-child. At times paths collided strongly, forcefully. I wonder where these paths might lead?

As I watched the movement between plant-child I started to ask what I could learn from the bending that takes place to make these paths. This chapter re-stories some of these movements and situates them as pedagogical questioning for those working with children.

\section{Paths Crossing}

Despite my best intentions to think posthumanly by noting the democracy of the entire classroom (Taylor \& Giugni, 2012), I still entered observations feeling like I was going to notice dominant ideologies of empathy, care, and love from child to plant. These were humanist concepts that I only acknowledged children's actions within. My observations did not show children watering plants or placing them in areas of sunlight or specific actions related to plant 
growth. This of course could have happened while I was not in the classroom observing. However, my experience encouraged me to shift and open my understanding of care between plant-child.

"What was it like sharing the class with plants?" I ask Gooey as he colours his art which he will later explain to me is a jungle plant.

"Shaking them around," he tells me.

"What did that do to the plants?" I question.

"Happy!" he exclaims.

"It made the plants happy?" I clarify.

"Yeah and it made me happy," Gooey tells me.

Kimmerer (2013) discusses the act of love and care as being a reciprocal relationship between humans and nature.

Knowing that you love the earth changes you, activates you to defend and protect and celebrate. But when you feel that the earth loves you in return, that feeling transforms the relationship from a one-way street into a sacred bond. (Kimmerer, 2013, p. 124-125)

The discourses of nature often focus on the one-way path of care from human to plant, but how is this care reciprocated? It is not uncommon to see children blurring the binaries between human/nature when they showcase the lively and animate aspects of the more-than-human world (Taylor, 2017). Gooey broke down these boundaries by including not only human experience to 
his perceptions when he explained that both he and the plants felt happiness within their interactions together.

The night before I brought the plants into the classroom I had nightmares that the children were dumping, spilling, and tearing all the plants. Anxiety of the unknown spread through my stomach as nausea formed leading up to the first moments of plant-childclassroom interaction. The first morning with the plants they are spread out on low shelves and on the carpeted floor based on children's suggestions.

Cleah is crawling around the base of Areca Palm before standing up and exclaiming, "It's raining," as she pulls the leaves over her head like an umbrella.

Meanwhile Gooey is yelling "plants" repeatedly while pointing, only quieting when his excitement is acknowledged. Areca's leaves brush against their faces. "It tickles," Gooey says before saying to his peers, "Let's touch the plants." Unicorn comes and circles around Areca before stopping and hiding behind, peering through at Gooey. Unicorn pulls Areca's branches around her body. Both Gooey and Unicorn pull roughly at these branches, bending them coarsely. 
Areca Palm moves with them. Unicorn goes over to Fern and pulls on their leaves. They break instantly, unlike sturdy Areca.

"It's going to turn into a caterpillar," she says as she holds up the foliage for me to see. I smile and she tosses the piece to the ground where it lies disconnected from its life force, motionless.

Throughout the research large Areca Palm drew both my own attention and the children's attention often. The movement that took place between child-palm was wider, bigger, and louder. I watched as Cleah lied underneath Areca's branches, resting with a toy baby. Cleah's body would come in and out of contact with Areca as Cleah rolled to different positions. Raya and Ronis roughly bounced toy stuffed animals and even books off the branches. Children would be playing nearby then pulled into contact with the plants briefly for moments that only lasted seconds as children would walk over and look at the plants, or touch them softly, before leaving. It took extra consideration on my part to observe the smaller moments of interaction.

The plants sit on the floor in the child-placed arrangement. Happy walks into the space with his eyes set on the bookshelf. As he enters the flowers on the plants draw his gaze. His body looks uncomfortable as he contorts it slightly to navigate around the plants which are in his path. They have interrupted his action slightly, reaching out with their needs. Their presence asks of him to be careful. He delicately steps around the pots without knocking any 
over, clearly concentrating to do so, grabs a book and leaves.

When Areca Palm was in the middle of the room and provided more space for children to interact, the children would run and crawl around the plant quickly and loudly. The strong branches would bend without breaking when children pulled roughly on them. When Areca was pushed to the side this type of movement was reduced. This made me think about the ways the early childhood classrooms are organized to draw attention to certain materials, such as setting out play stations. Nelson, Pacini-Ketchabaw, and Nxumalo (2018) argue that there is room to critical assess how colonial logics contribute to oppression and privilege through relational reciprocity. The design of the classroom promotes the importance of certain materials/species/bodies over others.

The movement of the children's bodies would push air towards the leaves of Areca Palm, waving them gently and leaving Areca almost in constant motion throughout the observations. When I first started growing seedlings several years ago I read somewhere to blow on them to mimic wind, making their roots grow stronger. I wonder what the rush of children's bodies in the classroom is doing to the plant's root system. I wonder if the constant touch and movement is hurting these plants or if it is strengthening them. Are the plants learning to grow with the children? The children's hands would dart out and reach for these slightly moving leaves, pulling their fingers down towards their end. They would spin their bodies around while moving past the branches that reached out over the walking paths. They would squint their eyes as the branches brushed against their faces as they moved along. The plants contributed to the movement of the children. The 
plants reached out and cared for the children and implemented agency within the actions of these relationship. The larger plants showed agency by initiating wide, vast, loud movements to the point that children were at times asked to slow down and control their movement to match the indoor class rules. At times children would play roughly with Areca Palm and I would step in to discuss how this hurt and damaged Areca. This point in the children's movement was much louder, rougher, and more chaotic than with the smaller plants which contorted children's movement and displayed agency in my observations through breakage before I could step in with discussion or before children's actions became loud/rough/chaotic. The smaller plants were able to navigate their fragility through damage. Larger Areca Palm however was more subject to the human created boundaries of what is expected behaviour and movement within a classroom. In return Areca required more human interception to protect them self as children explored these adult-created boundaries with rougher force. This movement could be explored by questioning how both plants and children learn to move from each other. Throughout the observations I saw the different ways that children moved depending on the plant they were near. Acknowledging plants' role in dropping delicate leaves, in growing hard-to-tear stems, in branches that move wildly with motion, shifts the human-centric thinking that creates value based on human ideals. Each of these plants were creating knowledge with the children and the ways that the classroom came together with this knowledge could be seen through their movement together.

How were the plants learning to move with the children? Right away the actions that took place between children and Areca Palm showed general principles of play as children created make-believe scenes and reimagined Areca as other objects. Adair and Doucet (2014) note, when play is universalized it makes assumptions about childhood that does not include racial and cultural context which can greatly influence the concept of play. Knight (2018) questions how 
play can be looked at from a non-human principle. Thinking with Knight (2018) and viewing play as movement between matter, these overlapping paths that form between plant-child could be questioned not only as how did the children play with the plants, but how did the plants play with the children? Bulldozer makes his way to the corner of the space and he is crouched down low, looking at me through Areca Palm's leaves. Areca breaks up the image of his face but our smiles make their way to each other. Bulldozer starts to giggle as he peeks through Areca at me. His laugh inspires my laugh. He crawls towards me under the branches. He gets closer and Areca is no longer breaking up the image of his face. We smile at each other. He moves his body into a cobra stretch, backs his body up, laughs, then crawls away quickly. There were moments in the observations that power dynamics between myself and the children were present as children at times would ask me if they could touch the plants. I attempted to minimize this by sending this question back to the children to decide themselves whether they think they could touch the plants. This moment with Bulldozer dismantled these dynamics as child-plant-adult entangled in a moment of play and laughter. Rautio and Jokinen (2015) write that when observing children as entangled assemblages with their environments "they are freed, for a moment, from themselves as individuals, from other people's thoughts and meanings, from being human, and from representing a certain developmental phase" (p. 12). Murris and Borcherds (2019) note that focusing on the engagement rather than the specific boundaries of child-plant-adult may 
dismantle hierarchies between categories. The engagements between plant-child continually provided moments to question these power dynamics. Taylor and Giugni (2012) recognize that power dynamics contribute to unequal hierarchies between more-than-human world but also between human worlds. Language used to separate plant-child-adult is unstable due its universalizing nature. Power is inserted into definitions as bodies/materials/species are construed to fit within these categories. Tsing (2013) notes that exploring how categories assemble is an aspect of understanding these dynamics. In this moment with Bulldozer I am not considered within my role of adult but instead within the action taking place. The relationships that formed in the classroom provided moments to question the ways that movement contributes or dismantles power dynamics. Who or what regulates these relationships? What role do plantchild-adult have in that regulation? As paths form between common worlds what responses are ignited?

As I come into the classroom this morning I see the plants have all been "put away" on the shelves. I ask Bulldozer and Gooey if they would like to help move them. As we start to move them Bulldozer grows wary of moving the plants that are extra tippy such as Strawberry Plant. His face looks worried at the prospect of moving the plants that might spill. His eyes widen, and he backs away slowly, shaking his head very slightly. He looks at me and tells me he doesn't want to move Strawberry Plant so I take them in my hands and ask him where they should go. Strawberry goes on the floor with the rest 
of the plants which have been placed in the middle of the carpet.

Cleah has joined and steps over Alyssums.

"I stepped over it," she shouts. Later, during my observations I note that I did not write down who stepped over the plant so I ask the group.

"I stepped over the plant because I wanted to touch it," Cleah informs me. There is a natural "path" that has been made by the parameter of the plants between the herbs and Lemon Tree and Cleah, Gooey, and Bulldozer start walking through it.

The path is just big enough for small feet to pass through. Cleah is called to the bathroom and when she returns she begins to step

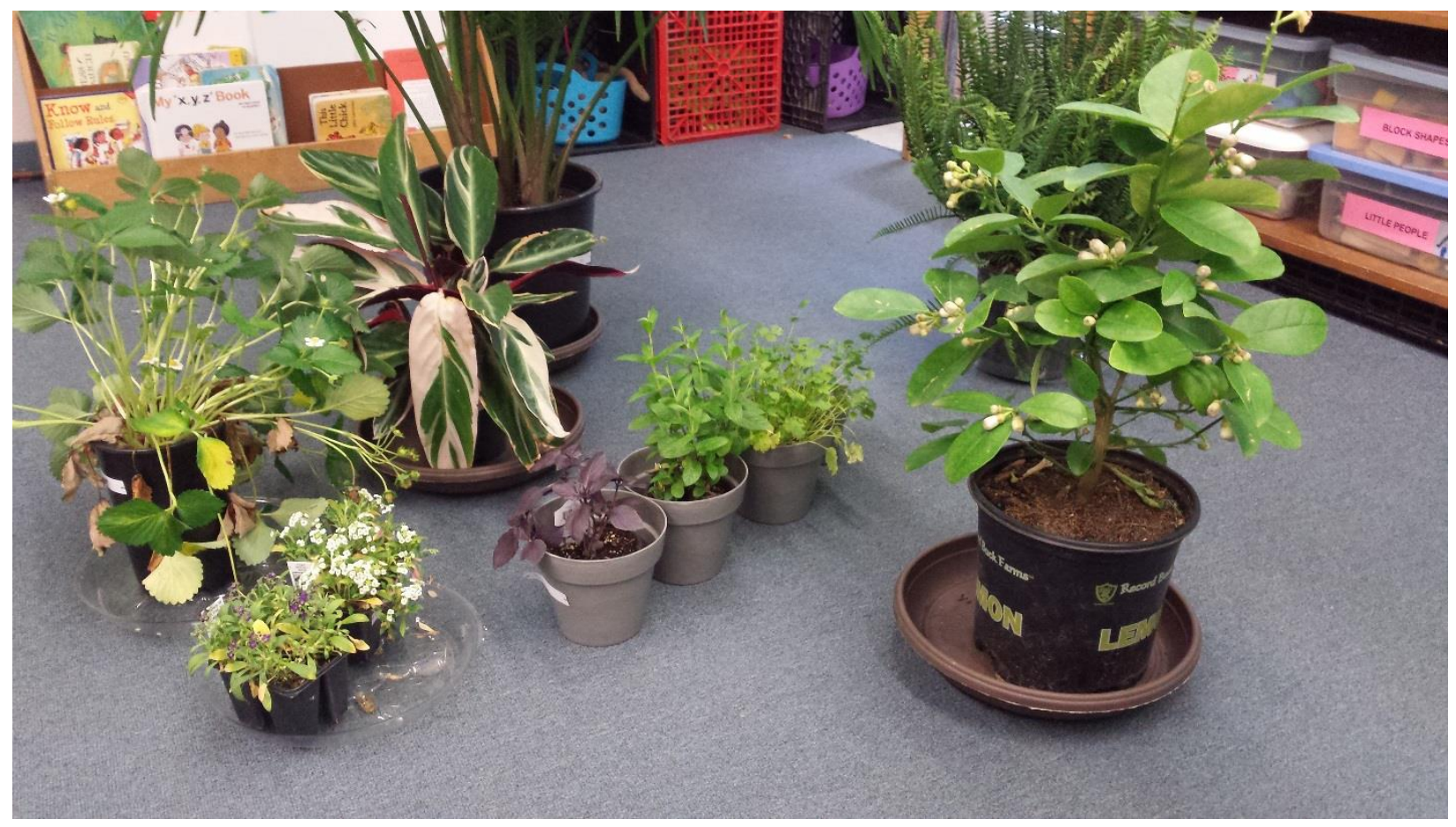


through the path again stating, "plants" as she walks. She cycles

through the path again, this time skipping. Cilantro wiggles from the brush of her leg. The path is not big enough to walk through without the plants contacting the bodies.

The more-than-human world and people are constantly engaging in a process of coevolution (Kimmerer, 2013; Myers, 2017a; \& Kummen, 2019). The plants and these children are entangling in a process of co-evolution. The plants are no longer in what might be considered "natural" habitats. Instead this garden in the classroom has been created, altering the paths of both child and plant. The concept of natural habitats separates human-nature from being entangled. $\quad$ As I write, disturbing accounts of the inhumane treatment of people attempting to migrate across borders is filling my news feed. As the landscapes of people's "homes" change, how will migration patterns adapt? What co-evolution is taking place between these choices, movements, actions, and the earth?

Throughout the time the plants spend in this specific path formation some children repeatedly walked, skipped, jumped through the path where some used it to get from one side of the class to the other. Much of human-centric development and progress pushes and moves the more-than-human world in precise ways to create opportunities for specific human movement: the development of cities, the "progress" of economy, the pursuit of travel. The plants urged children to contort their bodies to interact with this path, something the children were willing and able to do. What if we deeply observed the changes that are made to move through paths? A 
developmental lens might look at this moment and praise a child's ability to manipulate and control their body enough to walk through the narrow path. What if we made space to explore how the path came to be and what that means for the classroom as a whole?

As I watched these common worlds come together it was rare to see children move the plants out of their way when they played. They pushed the branches, damaged the leaves, and ignored the plants as the stems hovered over the play areas. Rarely did the children relocate these plants to get their own bodies in a different place unless specifically suggested by myself or other adults. There were many moments it would have been easier for children to create bigger spaces for their bodies. It would have been easy for them to move the plants to different locations, but they didn't. I wonder how these small moments of discomfort can be explored deeper within early childhood education, on a pedagogical level. How can children and families and communities be encouraged to question the discomfort that comes from having the more-thanhuman world in our "way"? How does this connect to colonial distribution and need to control and have power over the land? Is there room for our education system to explore how Areca Palm brushed against children's eyes as they walked into a path? Tsing (2013) notes that concepts of freedom are often navigated from a specifically human perspective due to religious notions of moral choice. In my notes to myself, scrawled across the page are the words "How are the plants reciprocating? How are the children reciprocating?" Both plant and child are forced into the classroom but what is their freedom, their agency within this control? Can the ways that plants and children bend and inform each other be explored as their agency in this space where both have little choice over their 
attendance? If this garden classroom continued longer, how would the children continually change and shift their ideas on where they think plants should be located in the classroom? How would the plants continually contribute to these decisions?

\section{Paths Colliding}

Gooey starts taking the potted plants from the shelf and putting them on the floor. Alyssums tip over and Gooey picks them back up and places them upright. Cleah starts helping move the herbs onto the floor.

Small Succulents tip and Gooey says, "Oopsie daisy," before placing them upright. The two children work together to move all the plants into a group on the floor. "We're putting them all over there so we can touch them," Gooey says out loud. They ask me to help move some of the larger plants to the location on the floor. "We have one more to move," Gooey says as he starts to push Areca Palm over. "We made it," he yells loudly, "There it's done!" he says.

"Yay!" Cleah exclaims. The plants are haphazardly spread out in one area of the floor space. "We did it together," Cleah says. Looking at the floor Cleah picks up a tiny lemon bud that was detached from the branch during the move. "A melon fell off," she says as she steps backwards and knocks Small Succulents over, spilling dirt on the 
carpet. The soil is dark and rich against the carpet. "I can put it back," she says as she starts to pile the dirt into the pot. She puts Living Stone and Small Succulents back in the pots they fell from and starts to pile dirt on top of them. As she scoops dirt from the floor it also starts spreading outwards on the carpet.

Gooey has started helping, "We're cleaning up the mess together," he says. The more they scoop the more the dirt is pushed outwards in all angles on the carpet. Recognizing that the dirt is starting to seep into the tiny knots of the carpet, I suggest getting a broom and the three of us work together to sweep up the dirt. As Cleah is helping she knocks over more plants which are dispersed across the floor in a tight arrangement, leaving little room to move.

In part of this moment Gooey and Cleah are showing cooperation and excitement about working together to clean up this mess. This could be interpreted as care for their environment or the plants and it could also be interpreted as knowing the rules. I did not explore this in the moment to try and wonder with them what it means to clean up the mess. There were several times when plants were knocked over and spilled. In many of these moments I stepped into the observation to help clean up. I was drawn into action because as the mess grew I worried about children being reprimanded for their actions. My own guilt mixed with my ethics made me feel I was responsible for this and brought me away from sitting with the discomfort of these moments. 
Pacini-Ketchabaw and Nxumalo (2015) discuss the unsettling that takes place when human-set boundaries are crossed by the more-than-human world. Sanitation, a dominant discourse within early childhood education, is prevalent in the regulations that mandate centres to sterilize outdoor materials before bringing them into the classroom. I winced at the pain in my hands as I created a fist and a new crack in my skin broke open and started bleeding. The sanitizer used in the childcare centre I worked at had started to tear away at my skin. Daily I cleaned cots, tables, toys, and bathrooms with this product as per health regulations.

Pacini-Ketchabaw and Nxumalo (2015) note that sanitation discourses can be traced back to Europe in the $19^{\text {th }}$ century. Cleaning up and controlling the mess became the main focus of moments where plants spilled and exploration into how the spills affected plants, the movement of the dirt, and even the action that caused the spill was less important in these moments. For myself the spills created the need to gain control of the environment again. When these plantchild relationships entangle and disrupt the tidiness of the classroom, what are we valuing most in these moments? Sanitation is a dominant discourse that is often unquestioned in childcare. Disrupting this and exploring the complexity of plant-spills resists controls placed on the system and enters those willing into an action of ethical engagement (Blaise, Hamm, \& Iorio, 2017) Lily walks into the play area where the plants are all located together on the floor. She is the only child in the space and as she steps towards the plants she knocks over Small Succulents who had been tipped over earlier by Cleah. She ignores this tipped plant and 
steps over them, reaching for Areca Palm as their leaves reach out over top of the entire scene. Areca traces their leaves through Lily's

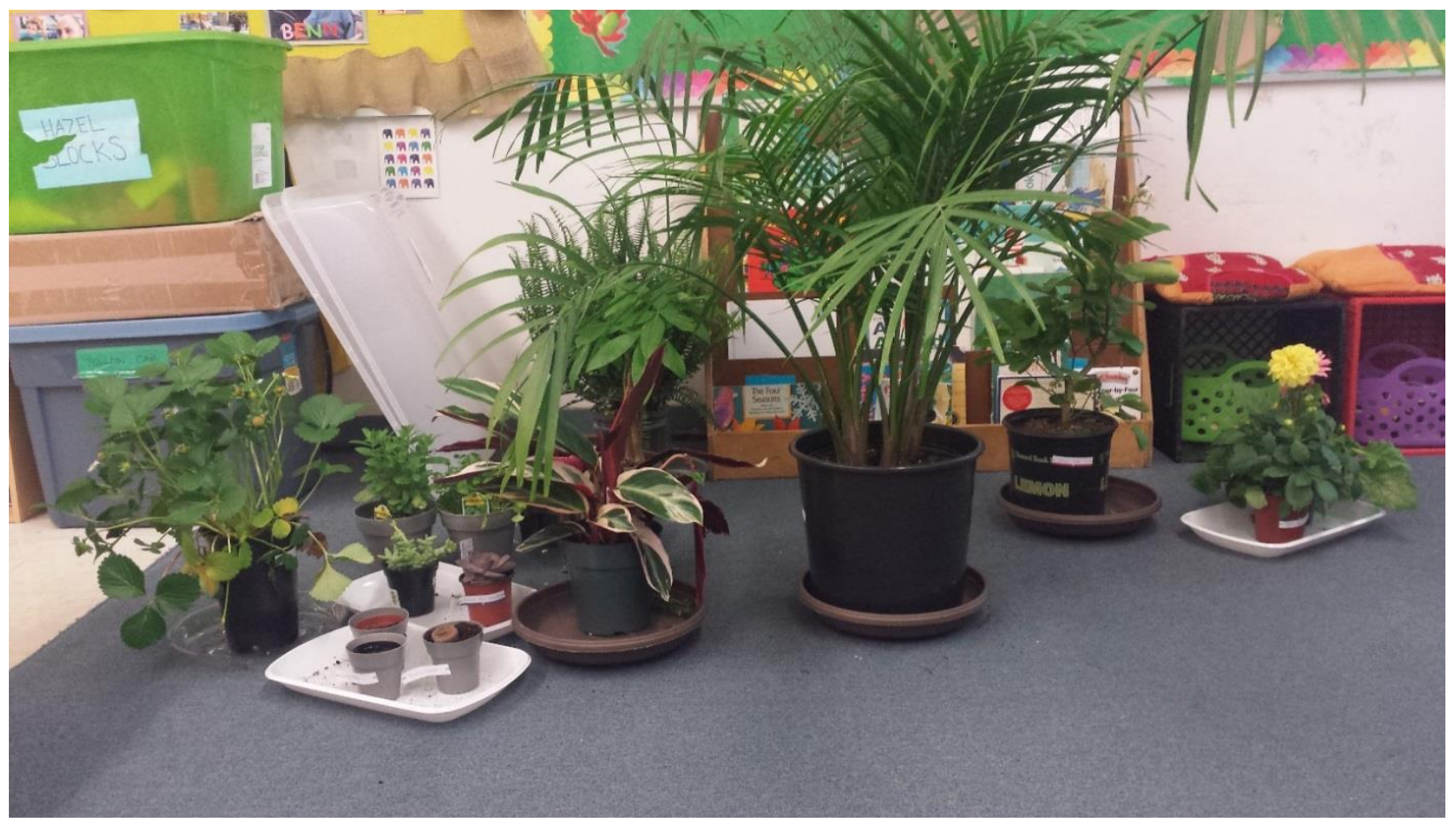

fingers as Lily silently looks at me, her eyes wide. I point to tippedover-Succulents and Lily continues to stare at me silently. I suggest ways that we could clean up the plant and she again continues to stare.

"You're not going to get in trouble for knocking over the plant," I quietly tell her, reading her body language as fear.

"They are on the ground. We should move them," Lily tells me as she watches me clean up Succulents without helping. Later during the 
art narrative process, I ask Lily if she remembers this moment and what she thought about the plants spilling.

"I think they're spitting out water," Lily tells me. She continues to tell me that she thinks the plants were spitting and when I ask her what else they do she informs me that "They do some stuff that's really gross." She goes on to explain that they spit water and food but they never eat any treats because they don't have any mouths. "They do have mouths!" Gooey pipes in as he works on his art beside her.

Lily clarifies that some plants do indeed have mouths, "Squirty plants have mouths, I know. I know that there are squirties that are plants and they spill." In this rendition of Lily's, it is the plants that are responsible for mess.

Lily was one child who often showed great concern about the plant's location and rules surrounding the plants. She was also the only child who asked me where the plants came from, navigating the understanding of the relationships that led the plants into the classroom. During the assent process with Lily, while I was explaining that we would be sharing space with plants for the research project she asked me, "where will we play?” In response I asked Lily how she has room to play when there are other children and materials in the classroom. From here Lily 
distinguished that she believed there should be a "no touching" rule about the plants which then led to discussion around gentle touch. During the art narrative process, I asked Lily what she thought other classes should know if they wanted to share indoor space with plants. "They need to know no breaking. They just need to be careful," she told me. Lily's concerns showed how the classroom space is controlled by humans and that the plants had the capability to disrupt the rules enforced on the space. $\quad$ Four bodies have started interacting with the plants in the play area. The noise is escalating and the movement is quick and forceful. Children are shaking the plants and running around the plants. I brought too many plants I think to myself, instantly concerned with the safety and management of the children bodies.

For Lily, when plants spilled the solution was not to clean them up and engage with the complicated mess, it was to remove the plants from the play area. Similarly to the children the plants were unpredictable; neither had a set location in the classroom unlike the rest of the materials. $\quad$ Over the two weeks of observations I would come into the classroom in the morning and often ask the children if they would like to move the plants from the shelves where they had been put away for group activity and nap time the day before. The children would place the plants disorderly throughout the classroom. As the days passed, I noticed the plants started to be incorporated in the classroom setup. The final days of 


\section{observations I came in to find the plants beautifully and neatly}

\section{displayed on the toy tables set out throughout the classroom.}

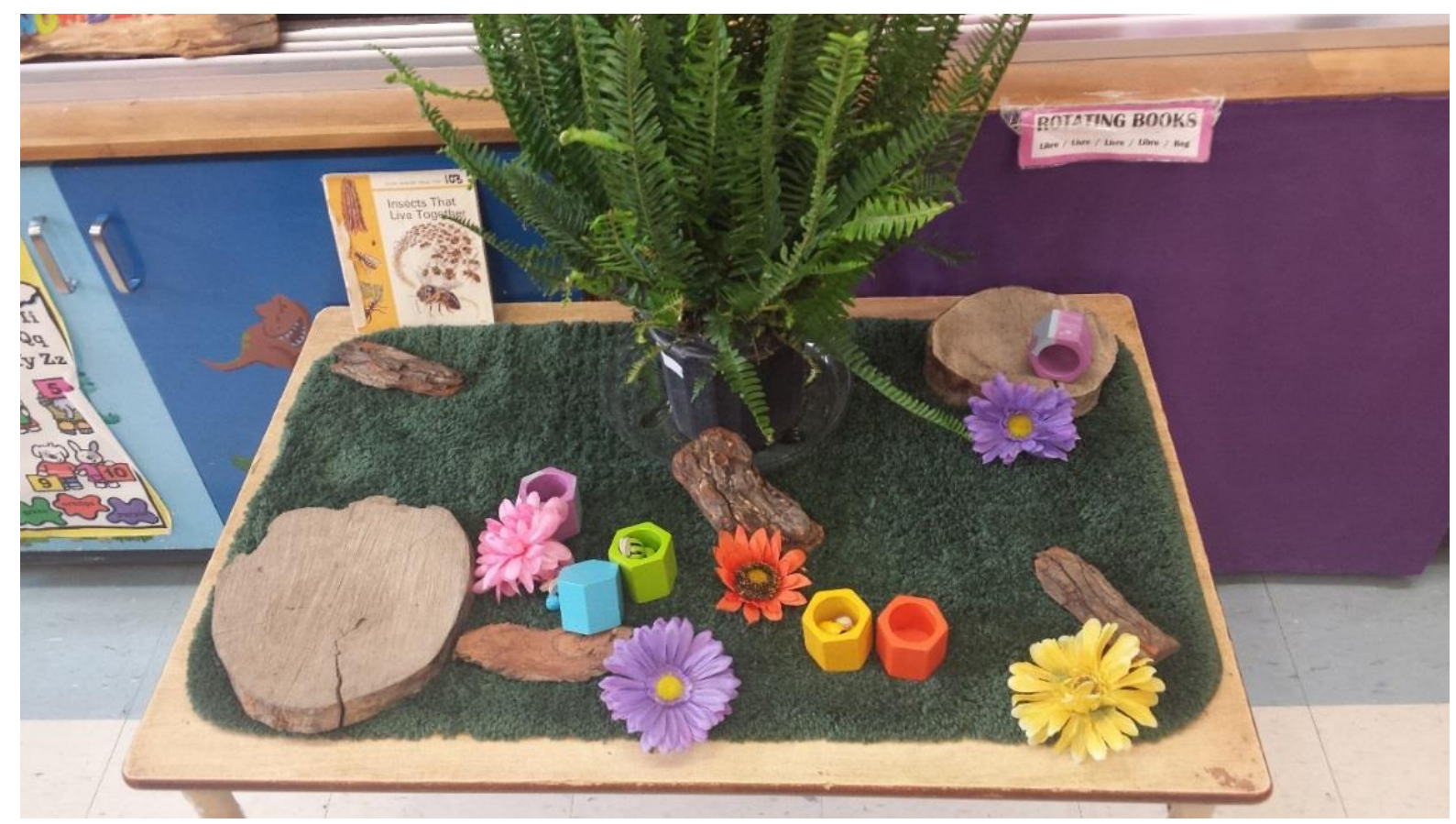

Within the dominant ideologies of the early learning room the plants provided

opportunities for "mistakes" or "accidents" regarding collision of paths/spills. Enforcing controlled locations and rules helps to negate these moments and can be seen in the set-up of many of the materials within early learning rooms. The bodies of children are also encompassed within these rules as their movements are guided by the routines and rules of the classroom. As an early childhood educator myself I empathize with this; I lived and breathed this as an educator. The pressures of large group dynamics mixed with regulations informs a desire for this organization. In decentering human desire as the primary aspect of organization I wonder how the common good for both human and more-than-human can be explored within the rules of organization and routine. Who and what makes these rules? Who and what are affected by these rules and how? Myers (2017b) asks not only "what worlds are we cultivating in our gardens, but 
also, what worlds are our gardens designed to reproduce? Into what futures are we taking root?" (p. 298). When organizing and enforcing rules on plants within the classroom how does this build an education system that re-enforces human-control-over-others rather than human-withothers relationships? For educators this requires a deep in-depth look at not only how the morethan-human others are being regulated, but how human bodies are being organized and regulated in the classroom as well.

The plants are put up on shelves this morning so when I come in I ask Green if he would like to help me move the plants.

"Where should we put them?" I ask him and he tells me they should go on the tables this morning. He is referring to the different stations that are set up around the classroom with different toys on them. Each day a new activity is set up on each table. Green starts to move the plants and I slowly back out of the action to observe.

"This one's very very growing," Green says about Living Stone. The plants are dispersed on the different tables. Cleah is playing at one of the tables. She shakes one of the toys which in turn shakes a piece of cardboard that is being used as a separator to distinguish different play centres. This shakes Spearmint which has been placed nearby. 
Lily comes over to me and asks, "Can I bring the plants over?" I tell her yes and she brings Stromanthe Triostar over to me an asks where she can move it.

"Where do you think?" I ask her.

"Here," she says as she moves to a low level shelf nearby.

"Why do you want to put it there?" I ask her.

"It's safe there," she informs me.

Taylor and Giugni (2012) note that ethical questioning is central to common world practice. The merging of paths is filled with a depth of ethical considerations so complicated that arguably it is not possible to attune to all of them. What is attuned to is an obligation to values. In my sampling I noted there were several ethical questions that I spent limited critical time with in order to make collecting the plants easier on myself. Within the classroom what responsibility does the community hold, what values would be attuned to? Who and what benefits from having these plants in the classroom? Myers (2017b) argues that looking at the ways that plant and human come together to form gardens, humans do not yet know what is best/proper/good for the plants. Lily is navigating ethics when she considers the safety of the plants but she is also navigating power. She seeks my adult permission to move the plants before doing so, showing that I am situated in the classroom as someone to make that decision. These scenarios draw upon power as they are becoming. 
I notice that at one of the play tables Succulents have spilled and dirt is spread on the table and floor. Lily notices me observing and comes over to the table. The yellow and pink flowers blossoming on Gerber Daisy and Dahlia call her attention as she touches each of them. I notice that one of the flowers has been plucked off the stem and is sitting precariously on the top of the plant. YES steps in the dirt on the floor as she walks by. Her foot pulls the soil outwards, spreading it slightly across the linoleum. Throughout the observations there was damage done to the plants. Over the days I would notice children holding the tiny, juicy succulent leaves that had come off Burro's Tail. Children would hold the leaves in their palms like tiny jewels, their eyes wide. Burro's Tail loses these pearls easily upon touch. As I walk by Burro's Tail it is nearly impossible to resist popping the small leaves between my fingers, their feel and texture inspires squeezing. How can the safety of the plants be renegotiated in ways that do not reinforce human-centred responsibility? As the tiny succulent beads fell from their stem into the palms of children, can the solution of "don't touch" or "move the plants" be complimented or replaced with the more complex question of "what does this teach us about how we live together?" 


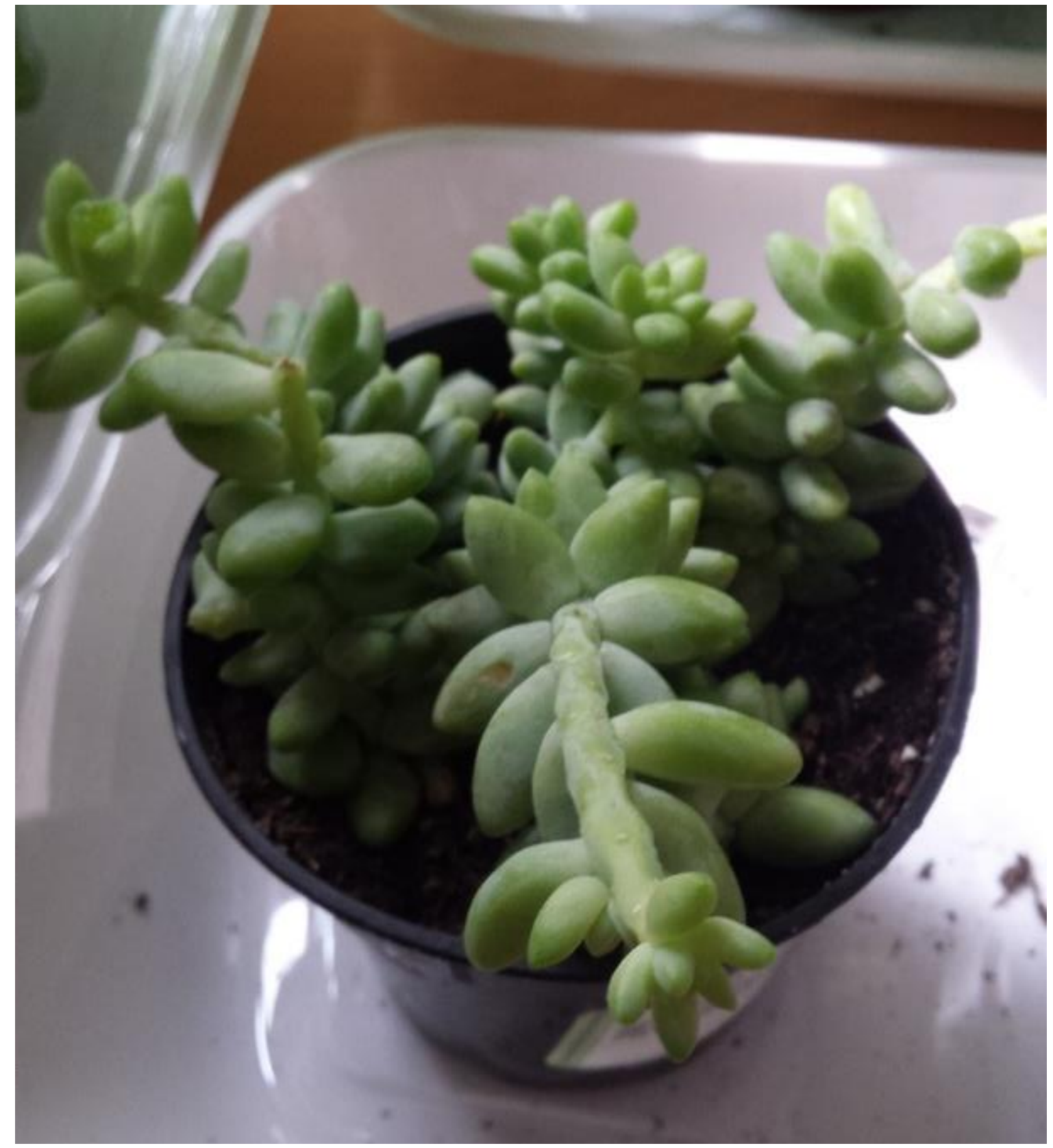

Urban (2018) writes that complexity is necessary to understanding new knowledge. The linear development model uses an already-certain destination to understand children and does not include plant knowledge at all. Urban (2018) notes that this linear perspective limits who and what can contribute to knowledge. Imagine how complex our relationships could be if all knowledge was welcomed into education systems rather than assimilating to a Euro-centric 
format. What could be learned? What could be questioned? Throughout my time at the research site Lily brought up concerns about the plants. Ethically, it was important for me to understand if Lily felt negatively about participating in the research and if there was anything I could do to rectify this. However, she confirmed that she enjoyed sharing the space with plants and when I asked her why she told me, "Because they're special and they need to grow." Lily's complicated relationship with the plants allowed room for moments that were uncomfortable for her. The relationship between Lily-Plant was not always romantically positive. Yet, a sense of belonging and acceptance was shown as she explains that her enjoyment of the plants included needs other than her own.

\section{Paths Unconnected}

"What is that lemon tree doing," Gooey asks me "is it still a

lemon?" I tell him that the lemon tree will grow the tiny buds into

lemons if it is healthy.

"What are those lemons doing?" he asks again.

"What do you think?" I reply.

"They are so cute," he responds. I point out the flowers on the tree, that this is where the plant will make a lemon if it is healthy.

"Are these still flowers?" he asks me, pointing to the white blossoms.

"What do you think?" I again reply.

"They are flowers," he tells me. 


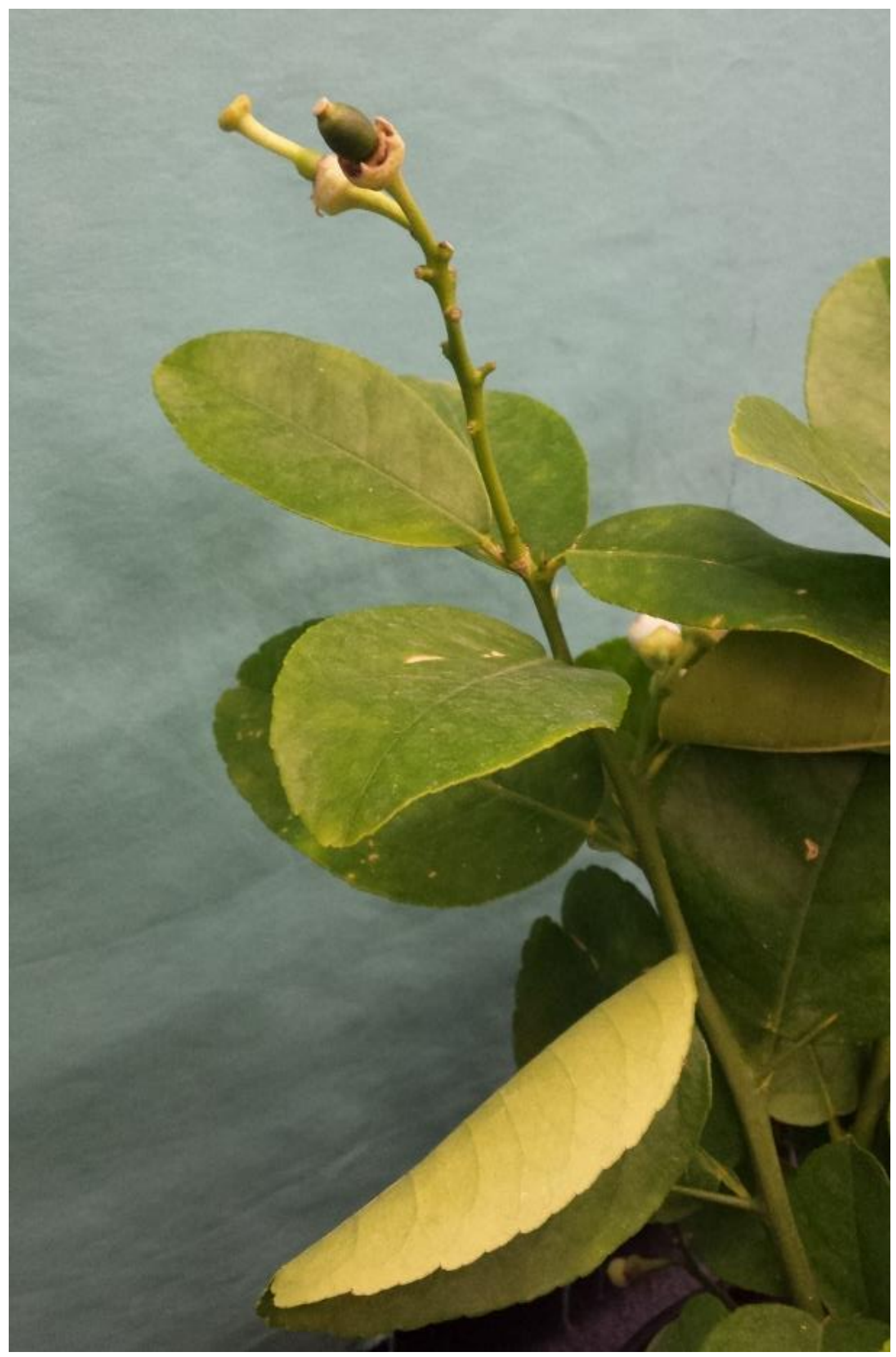


This moment is one where I do not believe I was understanding what Gooey was asking me. In it represents the fallacy of "capturing" voice within research. What was the lemon tree doing? Myers (2017a) writes about the ever-changing ways that plants are "doing" regardless of human noticing or interacting. Myers (2016) poetically describes photosynthesis, stating "textbook diagrams familiar from high-school biology class are simplistic renderings of that utterly magical, totally cosmic alchemical process that tethers earthly plant life in reverent, rhythmic attention to the earth's solar source" (para. 1). As common worlds constantly engage, plants have a form of power and control within the interactions and relations.

As Ronis and Raya walk by the table Strawberry Plant calls them over.

"There's a strawberry," Raya says as she comes closer to the plant, pointing out the berries which are still quite green. "Another strawberry," Ronis says, "How did that happen?" Raya looks at Strawberry Plant, "It just did" she replies before they both walk away. In the classroom there are so many moments that negate the growth of the lemons. Will the plant get the right nutrients? Will we pick the lemons too soon? When we pick lemons does it encourage the tree to make more lemons? This relationship of evolution consistently brings human-more-than-human entities together. Neither are innocent or agentless in the relationship.

During the art narratives when I asked the children what do the plants $d o$ in the classroom almost everyone told me that they were growing. This question was then paired with asking what 
did you do with the plants? When I asked this question to YES, who I rarely saw interact with the plants during my observations, she told me, "I didn't touch them because they were so growing but now they're growing more and then they'll be big plants." When I asked why she didn't touch them YES told me she didn't need to. Through my observations alone it would have been easy to miss how YES was relating with the plants but despite her lack of physical interaction she was aware of the plants acting within the class. Moment after moment my observations felt dull to me when they lacked child interaction as my human eye was unable to observe the miniscule moments of ripening strawberries, of photosynthesis, of growth and the ways that children experienced this. One of the play tables has water toys and water set up on it. YES has come over to the station and is scooping the water. Fern, Strawberry Plant, and Living Stone sit at the table with her. YES is scooping water in and out of the bucket. Fern

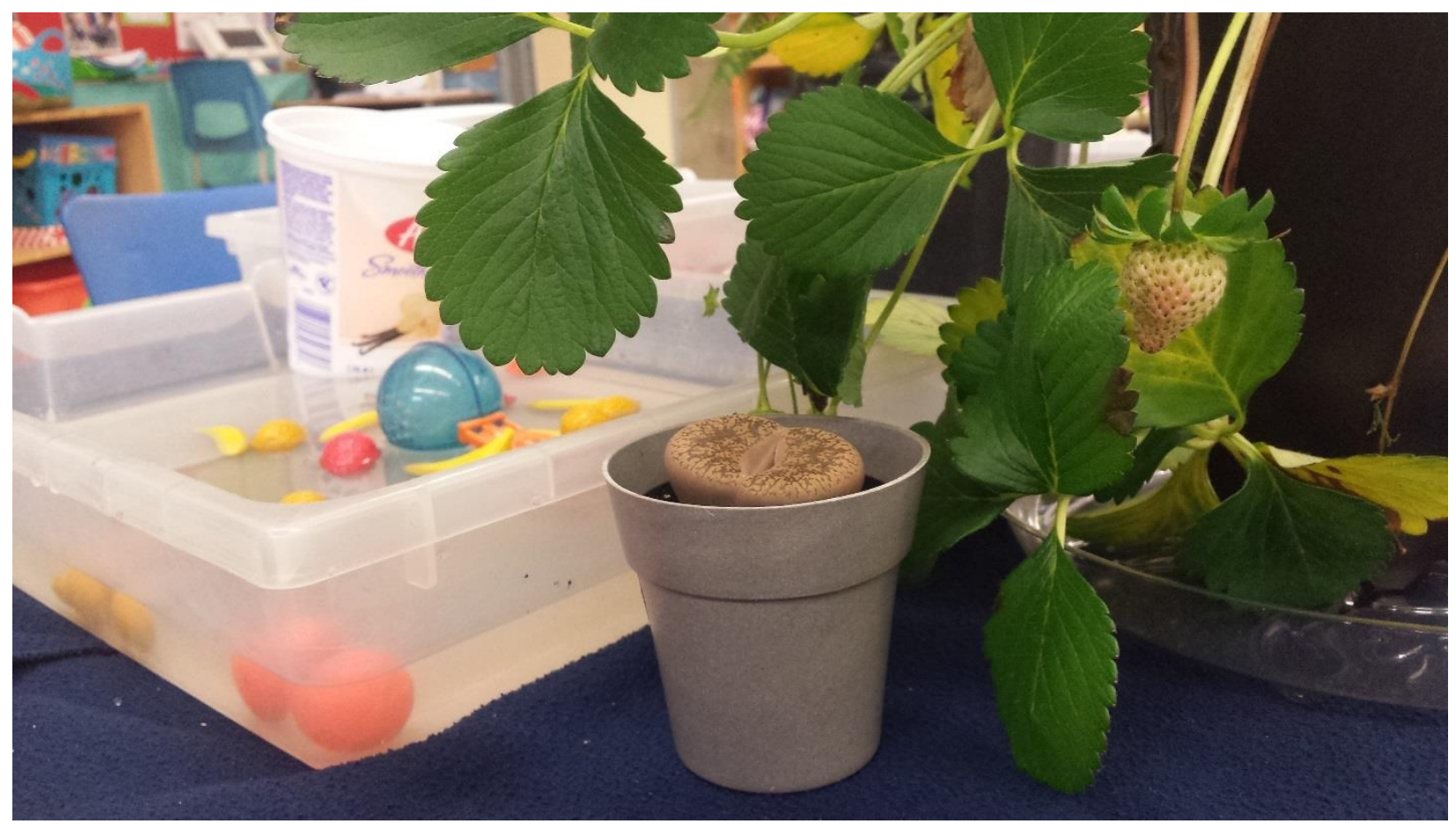


seems to be just out of reach in the middle of the table, but it is hard to tell because YES does not reach for Fern. Blue comes over to the water table and sits beside Strawberry. As Blue plays, her hand or occasionally the bucket she holds encounters Strawberry. Strawberry Plant's leaves bend over the water container just slightly.

Bringing together plant and child in an indoor classroom gives opportunity to explore what each are "doing" in relation rather than as separate entities. Taylor (2017) explains many stewardship narratives focus on the anthropocentric ways that humans can save the planet. Here in the small moments of the classroom I did not watch the developmental ways that children enforce this saviour control, but the way a classroom is built together. These smaller moments forced me to recognize that the plants were present within the interactions and to question what I thought I knew about that contact. Children's conscious interaction with the plants is not necessary for entanglement.

I ask Lily, Bulldozer, and Happy if I can bring Lemon Tree into the play area that they are playing in and they all agree. There are colourful toy cars dumped across the floor and I put Lemon in the middle of the area. Bulldozer taps a leaf then turns away and plays with the cars. As the three children play their backs are directed at Lemon Tree. Occasionally their feet tap the dish the plant is on, causing Lemon to wiggle. I can smell Lemon Blossoms as the 
movement pushes the smell towards my nose, but it does not seem to attract the children playing intently. It appears the children do not notice the presence at all, they are playing separately from each other. Some of them are singing loudly to themselves.

Occasionally someone will crash their cars against the pot of the plant. Lily's body taps the plant but she does not react as it shakes from this movement. Cleah walks into the play area and tries to navigate around Lemon Tree. Her ankle twists slightly as her feet tap up against the tree. The plant is pushing her off balance and it looks like she might fall.

"There's a plant in here," she says out loud before sitting down and playing with some cars nearby. Lily leans down towards the cars on the carpet and Lemon's leaves brush her face. Lily does not react and continues to play. As she continues to play she kicks her leg up and brings it down onto the tray Lemon Tree sits on. Lemon pushes up against the space Lily has to play in and leaves her little room to move freely. Lily looks at Lemon as she talks to herself. She reaches into the dirt and squeezes tightly then lets go. She is using a different voice during her play scenario, one that is slightly higher pitched. 
"We have a plant in here, it's giant and can't come into the house," she says. She turns away and her body presses up against Lemon as she faces the other direction and continues her play scene.

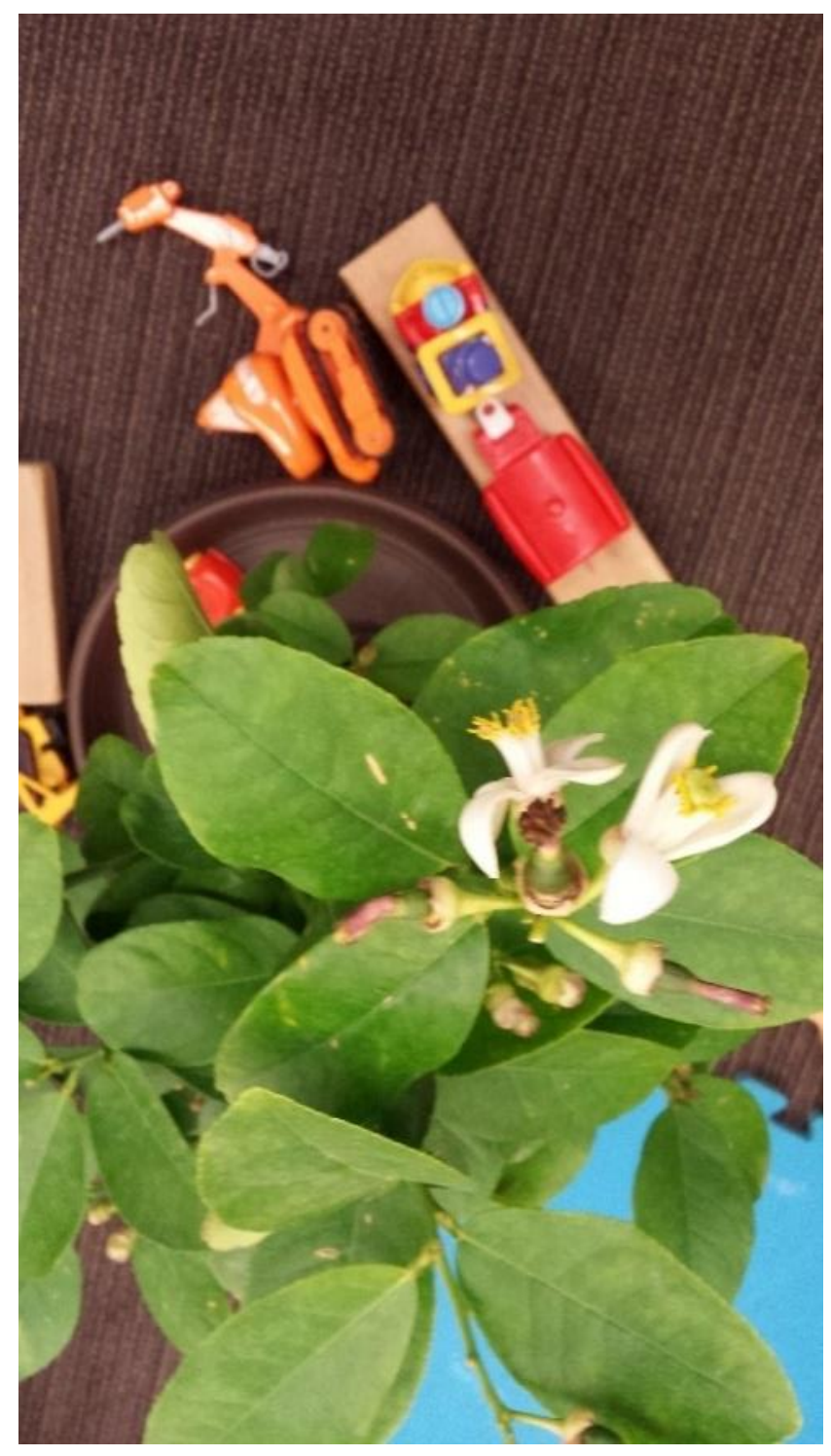

In many of my observations it seemed as if the plants were not having action within children's play. It was only in small moments of interaction, a look, a quick touch that I would see the connection. Expecting that simply providing free play with plants would positively 
influence children's ecological relationships is based on ideologies that limit and romanticize the influence of each entity (Taylor, 2017).

"What did the plants do in the class?" I ask Bulldozer who is working on his art narrative.

"They just play with us," he tells me.

"Oh, and what did you do with the plants?" I respond.

"I play with them," he tells me.

Programs that promote more "nature" play as being the key to environmental stewardship disregard the power dynamics associated within our stories and narratives of child and nature. Believing that only playing with plants would increase the desire to protect plants places humanchildren in control of these relationships. This idea is burdened by the narrative of wild/good nature and urban/bad nature (Taylor, 2017) which promotes a deficit view of some of these relationships and attempts to universalize these categories. There were many moments where children would step into an area with plants and exclaim how beautiful they were, before abruptly leaving. All the children told me they liked sharing the space with plants, however Unicorn also acknowledge that when she bumped her head on them it made her sad. Raya told me she liked the plants because they are, "so beautiful and green." Although I was thankful the experience was positive for children, it also showed how these relationships need critical engagement to question how power is inserted into narratives. What does it mean to share space beyond how the children feel? Realistically there were more moments within my observations where plant and child did not seem to be in contact with each other at all based on human- 
centred senses. As the plants and children shared this space the plants continued being present regardless of how or if the children noticed. The larger plants are sitting at the back of circle time with all the children looking attentively at the front. The children are giggling and singing a song together. Areca Palm waves so slightly as the group of children move. As the song gets bigger, louder, and the movement more exaggerated, Areca moves more. My perceptions of care were again dismantled in these moments when the children did not seem to interact with the plants. PaciniKetchabaw and Boucher (2019) note that more-than-human entities have unique ways of showing care which may not include humans at all. Re-writing the stories of children and plants I wonder how we can avoid these human-centered notions of the way that children care for plants and instead look at the ways they bend and learn from each other. Rather than look at what we can teach children about these relationships, I wonder what these already becoming relationships can continue to teach us? At the end of group circle time the group is dismissed and dispersed. Raya is sitting below the shelf with Strawberry Plant on it. She uses her two hands on the shelf to hoist her body upwards and she is now eyelevel to Strawberry. She stares for about ten seconds before leaving. When the class is emptied of children I go to take a picture of Strawberry from below, at the angle Raya would have been sitting. The vines are waving gently outwards 
to all angles of the classroom. If this was outside in the dirt the vines would be crawling and sprouting new plants. Some of the strawberries have started to blush red, ripening as each moment passes.

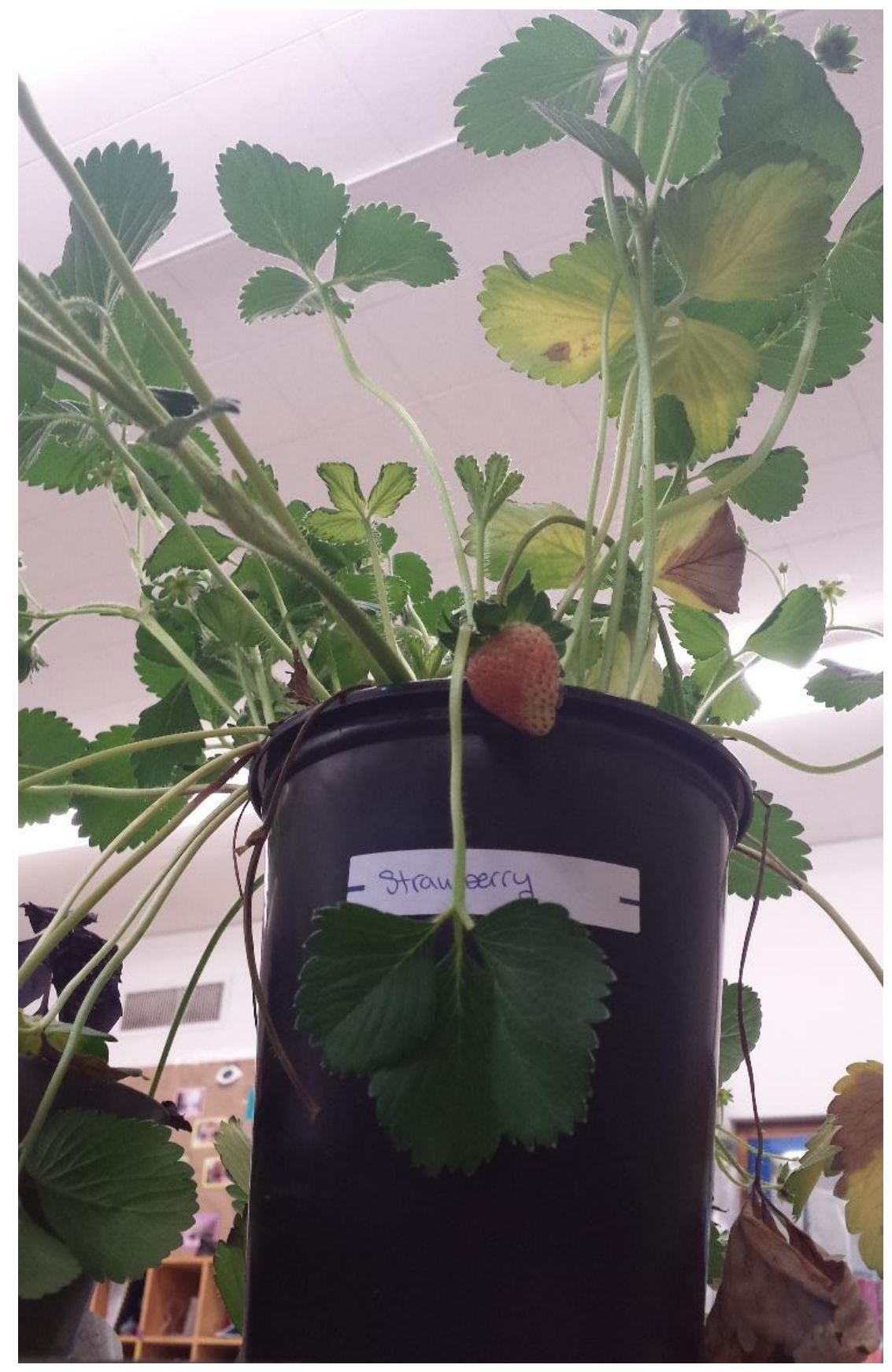




\section{Stop and Start}

This research re-stories the narratives of relationships between plant-child in a format that resists organization, classification, and universal answers. These aspects that are being resisted are tools that can be used within early childhood education systems to monitor, assess, and manage the development of children. However, the scale that children are monitored against is that of the Anthropocene, fueled by neoliberal and capitalist activity. Children's learning is based on how well they will fit into the norm of this society. Urgently, we need to make room for stories that do not continue to fit into this norm that we have created. The stories provided shift perspectives from being human-centred to instead include the agency of plants by looking at motion in a manner that does not abide to human ideals of value. Opening dialogue on what is valuable, on what is knowledge, pushes against narratives that promote humans and more-thanhuman others as resources. Here I have shared my experience of (re)considering an ECE classroom as a garden where both humans and more than human others contribute. Gardens are a representation of plant-human relations, a space which the mediated, entangled relations transform and manifest through growth (Myers, 2017b). How can classrooms be reconsidered as a garden? Those working in a garden need to maintain an understanding of the whole environment not only the individual components. What plants grow better together, the nutrients in the soil, temperature, the time you can give to the plot of land.

The story of the Three Sisters was told to me when I started gardening and later as I read the words of Robin Wall Kimmerer (2013) I learned this knowledge stemmed from Indigenous People who first worked the soil of North America. The Three Sisters refers to planting Corn, Pumpkin, and Bean together. The specific characteristcs of each plant support each other. Kimmerer (2013) writes, "The gifts of each are more fully expressed when they are nurtured together than alone. In ripe ears and swelling fruit, they counsel us that all gifts are multiplied in 
relationship. This is how the world keeps going." (p. 140). The garden provides a space to question design and the relationships that grow (Myers, 2017b). The developmental regime that leads early learning sets a stage that holds tight to the notion that the white, heterosexual, ablebodied adult is the normative category of knowledge and can inform what should be developing in the classroom. This exploration of ethics is shifted in a garden. Myers (2017b) writes that before people can ask what is proper for plants and people first we must explore "what relations these gardens set in motion" (p. 298). Unlike stages of development, there is no stop or start in a garden. These relations, the very structure of the universe, are continuous and ever-changing. With this motion/story/dance/path I explored what meaning we could make as these relations assembled. I watched and I shared as worlds came together and motion blossomed through these relations, rather than pulling them apart in order to understand them.

Thank you Garden. 


\section{APPENDIX A \\ Manager Information and Invitation Letter Can Ecological Relationships be Grown Indoors?}

Dear

My name is Leah Shoemaker and I am a graduate student in Ryerson's Master of Arts in Early Childhood Studies program. I am writing you because I am recruiting child-participants for my final research project. This research is being conducted under the supervision of Dr. Susan Jagger, faculty in the School of Early Childhood Studies department at Ryerson University. My study will be looking at children aged 2.5-4 years old and their relationships with indoor plants.

I would like to know if I may conduct my study at your preschool and recruit children from the class to participate. I will spend one month conducting research in their classroom (April 29-May 31, 2019).

The purpose of this study is to explore the interactions that young children have with indoor plants placed within their play area in a childcare facility. The research examines the different ways that children connect with plants and the personal perspectives that children have on the indoor plants. I hope that this study can contribute to a better understanding of ecological relationships and conservational attitudes.

Within the research I will spend two weeks volunteering at the centre to get to know the children and staff so that they are comfortable with my presence. I would then provide plants for the classroom which would be set up within the children's reach and eyesight, so they can interact, touch, and play with them. I will spend two weeks collecting data through observations, questions, and asking the children to share their ideas through art and narrative. I will not be collecting data from the staff. The study would take place during regular preschool hours.

This project has received ethical approval from the Ryerson Ethics Board. Before collecting data I will obtain signed family consent and child assent. The research is completely voluntary, and children and families can decide to withdraw from the research up until September 1, 2019. All personal information will be kept confidential and at no time will children's information be published or released to anyone other than my supervisor and myself.

The final report will be shared with you to make available to participating families and will posted on the Ryerson Digital Depository https://digital.library.ryerson.ca/. The findings will also be produced in story book form and shared with the preschool classroom. I will be submitting my research to be published in academic journals and presented at research conferences.

This research would take place between April 29-May 31, 2019. Please let me know if you would be interested in allowing me to conduct this research at your childcare facility. If you have any questions, please contact me or my supervisor Dr. Susan Jagger.

Leah Shoemaker, Principal Researcher

leah.shoemaker@ryerson.ca

Dr. Susan Jagger, Supervisor

416-979-5000, ext. 2517

susan.jagger@ ryerson.ca 
Sincerely,

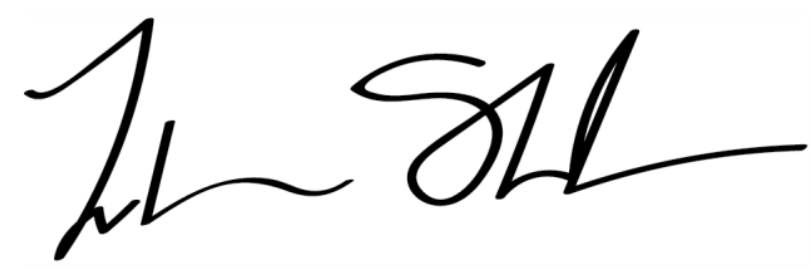

Leah Shoemaker

REB file number (2019-119) 


\section{APPENDIX B \\ Educator Consent Agreement \\ Can Ecological Relationships be Grown Indoors?}

You are being invited to consent to having a research study taking place in your preschool classroom. Please read this consent form so that you understand what your consent will involve. Before you consent to participate, please ask any questions to be sure you understand what consent will involve. Please return this form signed or unsigned in the envelope provided by April 26th, 2019.

\section{RESEARCH TITLE:}

Can Ecological Relationships be Grown Indoors?

\section{INVESTIGATORS:}

This research study is being conducted by Leah Shoemaker, a grad student in the Master of Arts in Early Childhood Studies program. It will be supervised by Dr. Susan Jagger, faculty in the School of Early Childhood Studies department at Ryerson University.

If you have any questions or concerns about the research, please contact Leah Shoemaker at leah.shoemaker@ryerson.ca.

\section{PURPOSE OF THE STUDY:}

This research is the final project in Ryerson's Master of Arts in Early Childhood Studies program. The purpose of this study is to explore the interactions that young children have with indoor plants placed within their play area in a childcare facility. The research is looking at the different ways that children connect to plants and the personal perspectives that children have on the indoor plants. I hope that this study can contribute to a better understanding of ecological relationships and conservational attitudes.

A maximum of 24 children between the ages of 2.5-5 years old will be recruited for this project. All children recruited are from the same preschool classroom. All other demographic criteria will be eligible for participation in this study.

\section{WHAT PARTICIPATION MEANS:}

- Prior to the research project data collection Leah will be volunteering at the childcare facility over a period of two weeks to build relationships with you and children. During this period all regular preschool activities can take place. Staff will not be included in the data of this research and the research is not judging, critiquing, or analysing the work of the staff.

- After this two-week volunteer period, Leah will individually explain the research project to each childparticipant who has family consent. At this time children will invited to choose to voluntarily assent to participate in the project. If a child chooses not to participate they will still be invited to join in on any activities, however they will not be included in the data. To ensure the voluntary nature of the study, it is important that staff do not try to persuade children to participate. If at anytime a child tells you they do not want to participate in the research you are asked to share this with Leah.

- The children will be invited to participate in small group discussions that explain the research project again. During this discussion they will be asked for ideas on what kind of plants they like and how they 
would like them set up in their classroom. Projected date: May $17^{\text {th }}, 2019$. You will be asked to suggest the best time to do this activity.

- Indoor plants will then be placed within one of the classroom play areas, incorporating the children's ideas where possible. During the design Leah would like your input on how to place plants within the play area. You will be asked to encourage children to interact, touch, and care for the plants. Projected date: May $20^{\text {th }}, 2019$.

- $\quad$ Over a two-week period (projected date: May $20^{\text {th }}-31^{\text {st }}, 2019$ ) Leah will spend mornings gathering data in the classroom by observing the children. During the observations Leah may ask children questions about their actions. At times I may audio record these questions to ensure they are transcribed properly. During this period the staff are encouraged to let children play, touch, move, and interact with the plants. If children damage plants that is okay and is a part of the research. You are asked to approach these situations in a way that you normally would.

- $\quad$ Throughout the study children will be invited to tell the researcher how they feel about the plants, what they know about the plants, and how they connect to the plants through art and story telling. All art will be photographed with names and identifying features removed. Original art will stay with the participants. Leah will coordinate with you on the best times to do these activities.

- The final research project will be provided in a storybook form for the classroom. The written report will be shared via email to families. This research will be submitted to academic journals for publication and presented at research conferences.

\section{DATA:}

This project will not include data from staff. The data collected from this study will be used to write the Masters Research Paper for the completion of Ryerson's Master of Arts in Early Childhood Studies program. Findings will also be disseminated through academic journal publications, research conference presentations, and in a childfriendly story book form.

The final research project will be provided in a storybook form for the classroom. The written report will be shared via email to families or can be found on the Ryerson Digital Depository at https://digital.library.ryerson.ca/.

Audio recordings will be transferred to a two-step authentication cloud storage system each day and deleted off the recording device. After five years the digital audio files will be deleted, and paper files will be paper shredded. The same process will be followed for photographs.

\section{POTENTIAL BENEFITS:}

The potential benefits from this project include the positive effects that the children in your class may experience from having their voices included and shared in a project. Indoor plants have also been shown to have positive effects on people in classrooms and offices and it is possible you and the children will benefit from such effects. It is my hope that this study will help to inform future research on early formation of empathy, care, and connection towards plants. I cannot guarantee, however, that you will receive any benefits from consenting to this study.

\section{WHAT ARE THE POTENTIAL RISKS TO YOU AS A PARTICIPANT:}

The research is being conducted in your preschool classroom and you may feel uncomfortable having someone observing the activities that take place. Please be ensured that this research is not observing your work as a staff and will not be collecting data from you. 
You may feel concerned that your privacy will be shared. Your identifying information will not be shared at any point in this study and all information will be stored in a locked cabinet in my supervisor's office. The childcare facility and the children's identity will not be shared in this research. During this research there may be instances when the plants upset the classroom routine, such as if a child damages a plant or spills dirt. To support you and the extra work that may come with this project, I will be spending two weeks volunteering in your classroom. I hope that this period can reduce some of the burden that may come with this project.

\section{CONFIDENTIALITY:}

During this study the only identifying information collected from you is this consent form. Your identifying information will not be will not be shared at any time during this study, including publication.

Physical data collected for this project will be stored in a locked cabinet within my supervisor's office. Digital data will be stored in a folder on a cloud storage device accessible through two-step, password protected, verification. All data will be destroyed after five years of the study end date.

Under section 125 of the Child, Youth and Family Services Act the researcher has duty to report if I have any reasonable grounds to suspect abuse. If at any time I am informed of abuse I have a legal responsibility to immediately contact Children's Aid Society.

If at any time abuse is suspected, confidentiality will be breached to immediately make a report to Children's Aid Society which will then determine whether further investigation in necessary. Potential legal charges and professional/family consequences would be determined after the investigation.

\section{VOLUNTARY CONSENT:}

Consent for this study is completely voluntary and your decision will not be shared with your manager or other staff. If you choose not to consent to this study, the research will not be conducted in your classroom. Your choice of whether to consent will not influence your future relations with Ryerson University or the investigator, Leah Shoemaker, or supervisor Dr. Susan Jagger, involved in the research.

QUESTIONS ABOUT THE STUDY: If you have any questions about the research, please ask. If you have questions later about the research, you may contact:

Leah Shoemaker, Principal Researcher leah.shoemaker@ryerson.ca
Dr. Susan Jagger, Supervisor

416-979-5000, ext. 2517

susan.jagger@ryerson.ca

This study has been reviewed by the Ryerson University Research Ethics Board. If you have questions regarding your rights as a participant in this study please contact:

Research Ethics Board

c/o Office of the Vice President, Research and Innovation

Ryerson University

350 Victoria Street

Toronto, ON M5B 2K3

416-979-5042

rebchair@ryerson.ca 


\section{CAN ECOLOGICAL RELATIONSHIPS BE GROWN INDOORS?}

\section{CONFIRMATION OF AGREEMENT:}

Your signature below indicates that you have read the information in this agreement and have had a chance to ask any questions you have about the study. Your signature also indicates that you agree to allow the study to take place in your classroom. You have been given a copy of this agreement.

You have been told that by signing this consent agreement you are not giving up any of your legal rights.

Please keep one copy of this agreement for yourself and return one copy to the researcher, sealed in the envelope provided.

This agreement is due back by April 26th, 2019.

Signature

Date

Name (print)

REB file number (2019-119) 


\section{APPENDIX C \\ Family Consent Agreement \\ Ryerson University}

You are being invited to consent for your child to choose to participate in a research study in their preschool classroom. Please read this consent form so that you understand what your child's participation will involve. Before you consent for your child to choose to participate, please ask any questions to be sure you understand what participation will involve. Please return this form signed or unsigned in the envelope provided by May $8^{\text {th }}$, 2019.

\section{RESEARCH TITLE:}

Can Ecological Relationships be Grown Indoors?

\section{INVESTIGATORS:}

This research study is being conducted by Leah Shoemaker, a grad student in the Master of Arts in Early Childhood Studies program. It will be supervised by Dr. Susan Jagger, faculty in the School of Early Childhood Studies department at Ryerson University.

If you have any questions or concerns about the research, please contact Leah Shoemaker at leah.shoemaker@ryerson.ca.

\section{PURPOSE OF THE STUDY:}

This research is the final project in Ryerson's Master of Arts in Early Childhood Studies program. The purpose of this study is to explore the interactions that young children have with indoor plants placed within their play area in a childcare facility. The research is looking at the different ways that children meaningfully connect to plants and the personal perspectives that children have on the indoor plants. I hope that this study can contribute to a better understanding of ecological relationships and conservational attitudes.

A maximum of 24 children between the ages of 2.5-5 years old will be recruited for this project. All children recruited are from the same preschool classroom. All other demographic criteria will be eligible for participation in this study.

\section{WHAT PARTICIPATION MEANS:}


- Prior to the research project data collection Leah will be volunteering at the childcare facility over a period of two weeks to build relationships with the staff and children (projected start day: May $6^{\text {th }}$ ).

- After this two-week volunteer period, Leah will individually explain the research project to each childparticipant who has family consent. At this time children will be invited to choose to voluntarily assent to participate in the project. On a sheet of paper, participants will be asked to mark a happy face for yes to participation, or a frowning face for no. Children will also be invited to assent to having their voices audiorecorded. They will be informed that they can change their mind at any time. If your child chooses not to participate they will still be invited to join in on any activities, however they will not be included in the data.

- The participants will be gathered in small group discussions to explain the research project again and be asked for ideas on what kind of plants they like and how they would like them set up in their classroom. Projected date: May $17^{\text {th }}, 2019$.

- Indoor plants will then be placed within one of the classroom play areas, incorporating the children's ideas where possible. Children will not be discouraged from interacting, touching, or caring for the plants. Projected date: May $20^{\text {th }}, 2019$.

- Over a two-week period (projected date: May $20^{\text {th }}-31^{\text {st }}, 2019$ ) Leah will spend mornings gathering data in the classroom by observing participants. During the observations Leah may ask participants questions about their actions. At times I may audio record these questions to ensure they are transcribed properly.

- Throughout the study participants will be invited to tell the researcher how they feel about the plants, what they know about the plants, and how they connect to the plants through art and story telling. All art will be photographed with the names covered. Original art will stay with the participants.

\section{POTENTIAL BENEFITS:}

The potential benefits from this project include the positive effects that children may experience from having their voices included and shared in a project. Indoor plants have also been shown to have positive effects on people in classrooms and offices and it is possible participants will benefit from such effects. It is my hope that this study will help to inform future research on early formation of empathy, care, and connection towards plants. I cannot guarantee, however, that your child will receive any benefits from participating in this study.

\section{DATA:}

The data collected from this study will be used to write the Masters Research Paper for the completion of Ryerson's Master of Arts in Early Childhood Studies program. Findings will also be disseminated through academic journal publications, research conference presentations, and in a child-friendly story book form.

The final research project will be provided in a storybook form for the classroom. The written report will be shared via email to families or can be found on the Ryerson Digital Depository at https://digital.library.ryerson.ca/. 
Audio recordings will be transferred to a two-step authentication cloud storage system each day and deleted off the recording device. After five years the digital audio files will be deleted and paper files will be paper shredded. The same process will be followed for photographs.

\section{WHAT ARE THE POTENTIAL RISKS TO YOU AS A PARTICIPANT:}

This research is conducted with children, who are considered a vulnerable group within society. Participants are at low risk of feeling discomfort due to the power dynamic between researcher and child. A two-week volunteer period has been scheduled to ensure everyone involved is more comfortable with the researcher in their space. To minimize risk all participants who have been given consent to participate in this study will also be given an opportunity to assent to the project and decide for themselves if they would like to participate. Their participation in this project will be completely voluntary, meaning at any time they can choose to no longer participate with zero repercussions. The researcher will not be participating in classroom management or behaviour of children, to increase the understanding of the voluntary nature of the project. Before data collection and assent is collected the project will be discussed in an age-appropriate way for participants. Children can choose to participate in certain aspects of the research and not others, their participation is completely voluntary.

\section{CONFIDENTIALITY:}

Your child's identity will be confidential throughout the entire research project, including publication. Names of children will be given a pseudonym and at no time will the childcare facility be identified. Children will be given the opportunity to choose their own pseudonym and if their choice is any way distinguishable to who they are the researcher will choose an alternative pseudonym.

Physical data collected for this project will be stored in a locked cabinet within my supervisor's office. Digital data will be stored in a folder on a cloud storage device accessible through two-step, password protected, verification. All personal data will be destroyed after five years of the study end date.

Under section 125 of the Child, Youth and Family Services Act the researcher has duty to report if I have any reasonable grounds to suspect abuse. If at any time I am informed of abuse I have a legal responsibility to immediately contact Children's Aid Society.

If at any time abuse is suspected, confidentiality will be breached to immediately make a report to Children's Aid Society which will then determine whether further investigation in necessary. Potential legal charges and professional/family consequences would be determined after the investigation.

\section{VOLUNTARY PARTICIPATION AND WITHDRAWAL:}


Participation in this study is completely voluntary for your child. If at any time during the research, you or your child would like to withdraw there will be no negative consequences. Data that has been collected up until that point will be destroyed at the end of the data collection period. If you choose to withdraw your child after the data collection period, the data will be destroyed immediately. Your choice of whether to consent for your child to participate will not influence future relations with the School of Early Childhood Studies at Ryerson University or the investigator, Leah Shoemaker, or supervisor Dr. Susan Jagger. You may withdraw consent up until September 1, 2019, after which the project will be made available to public through Ryerson University.

All children who have been given family consent to choose to participate in the research will also be asked if they would like to assent to the project. If a child does not want to participate even if they have family consent, their choice will be the guiding factor to whether they are included in the data collection. All children within the classroom will be invited to participate in group and art activities and only those with consent and assent will be included in data.

QUESTIONS ABOUT THE STUDY: If you have any questions about the research, please ask. If you have questions later about the research, you may contact:

Leah Shoemaker, Principal Researcher

leah.shoemaker@ryerson.ca
Dr. Susan Jagger, Supervisor

416-979-5000, ext. 2517

susan.jagger@ryerson.ca

This study has been reviewed by the Ryerson University Research Ethics Board. If you have questions regarding your rights as a participant in this study please contact:

Research Ethics Board

c/o Office of the Vice President, Research and Innovation

Ryerson University

350 Victoria Street

Toronto, ON M5B 2K3

416-979-5042

rebchair@ryerson.ca 


\section{CAN ECOLOGICAL RELATIONSHIPS BE GROWN INDOORS?}

\section{CONFIRMATION OF AGREEMENT:}

Your signature below indicates that you have read the information in this agreement and have had a chance to ask any questions you have about the study. Your signature also indicates that you agree to your child choosing to participate in the study and have been told that you can change your mind and withdraw your consent for your child to participate at any time. You have been given a copy of this agreement.

You have been told that by signing this consent agreement you are not giving up any of your legal rights.

Please keep one copy of this agreement for yourself and return one copy to your child's preschool, sealed in the envelope provided.

This agreement is due back by May $8^{\text {th }}, 2019$.

Name of Child (print)

I agree for my child to choose to be audio recorded for the purposes of this study. I understand how these recordings will be stored and destroyed.

If yes, please sign below, leaving this blank signifies that you do not given consent for your child to choose to be audio recorded. 


\section{APPENDIX D \\ Child Information Script to be Read During Assent Process Ryerson University}

\section{TITLE:}

Can Ecological Relationships be Grown Indoors?

\section{INVESTIGATORS:}

My name is Leah Shoemaker and I am a student at Ryerson University. Part of my school work is to do a big project.

\section{WHAT IS RESEARCH AND WHY I AM DOING IT:}

My project is also called a research study. This means I have a question and I want to find an answer. I want to know what you think, feel, and know about plants when they are in the placed in your indoor play spaces. There is a lot of information on how children enjoy nature outside, but I want to know how children enjoy nature inside. A research study is something I am doing to try and find out answers to my question and I want to know if you want to be a part of my research.

\section{IF YOU ARE A PART OF THE RESEARCH:}

You can choose to take part in the research if you want. If you want to be a part of the research now, but later you don't want to be a part of it, that is okay too. You can always change your mind. You can use your words to say no, you can shake your head, walk away, or just not talk to me and I will know to ask you if you want to keep being a part of the research. Even if you don't want to be a part of the research you can still spend time with me and do all of the activities with me.

If you are a part of this research I am going to ask you and your friends to come together as a group and tell me what you like about plants and how you would like the plants to be put in your play area.

Then I am going to put plants in your play area and watch what you and your classmates do with the plants for ten days.

I might ask you questions about why you did something, but you don't ever have to answer any questions if you don't want to. You can use your words to say no, you can shake your head, walk away, or just not talk to me.

I will ask you if it is okay for me to audio-record your voice so that I can be sure to get your answer right. 
You will be invited to share what you think about the plants using art or by telling me a story about the plants.

After, I will create a story book with your answers to my question and I will give that to your class to read. I will also share the answers I find with other adults through writing and presentations.

\section{REASONS YOU MIGHT LIKE THE RESEARCH:}

You are going to get to share your ideas about the plants and I will share that with other people, you might like that. You might really enjoy the plants in your play area, but you might not.

\section{REASONS YOU MIGHT NOT LIKE THE RESEARCH:}

You might not want to answer my questions and you don't have to. I am not going to get you in trouble and you never have to answer my questions. You have the right to tell me no and I must listen. You can walk away, shake your head, or just not answer and I will leave you alone. You might want to stop being a part of the research and that is okay, you can tell me this and you won't get in trouble.

\section{PRIVACY:}

I will not share your name or age or any information that will let other people know who you are in my research. You can pick a fake name and I will call you by that name in my research.

If you tell me that someone has hurt you or another child, I must share this to people that work to protect children so they can help you. I will have to share with them names and any other information that might help them protect you or your classmates.

\section{YOUR CHOICE:}

You don't have to be a part of my research. You can tell me you don't want to be a part of it at any time and I must to listen to you, that is one of your rights. You are not going to be in any trouble if you don't want to be a part of this research. Even if you do not want to be a part of the research you can still spend time with me, enjoy the plants, and do any activities that I bring to the classroom.

\section{DO YOU HAVE ANY QUESTIONS ABOUT THE RESEARCH?}

\section{ASSENT PROCESS:}

Proceed to the assent process using the Child Assent Cards, Appendix D. Ask children to mark the green happy face on the card if they want to be a part of the research or the red frown if they don't want to be a part of the research.

REB file number (2019-119) 


\section{APPENDIX E}

\section{Child Assent Card \\ Ryerson University}

TITLE: Can Ecological Relationships be Grown Indoors?

INVESTIGATORS: Leah Shoemaker

ASSENT: Children can mark the face to sign for assent

Child's Name:

Date:

Yes I want to participate

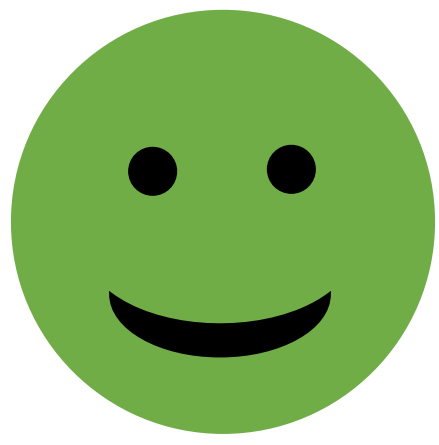

No I don't want to participate

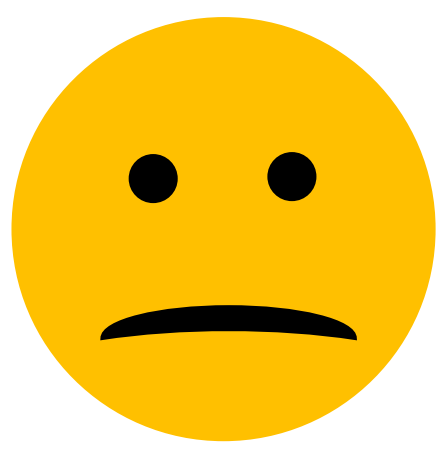

Yes, I am okay having my voice recorded

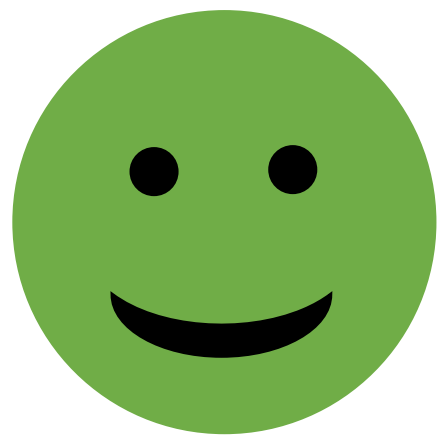

No I don't want my voice recorded

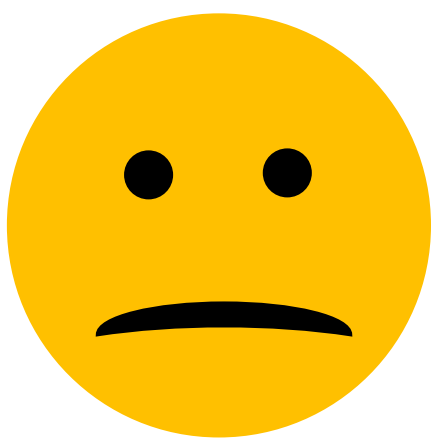

REB file number (2019-119) 


\section{APPENDIX F Sharing Circle/Group Discussion Guiding Questions}

This semi-structured script is to be used during the sharing circle/group discussion portion of the research design, projected May $17^{\text {th }}, 2019$.

Chart board paper will be set up for the researcher to record group answers on how they would like plants to be set up in their classroom. Children who do not have consent and assent to participate will have their answers recorded in a slightly different colour and these will not be included in the data, however they will be included in the set up of the classroom if possible. This discussion will be done in groups of maximum 16 children.

\section{TITLE:}

Can Ecological Relationships be Grown Indoors?

\section{INVESTIGATORS:}

This research study is being done by me, Leah Shoemaker, a student at Ryerson University.

\section{WHAT IS RESEARCH AND WHY I AM DOING IT?}

I am doing a research study which means I have a question and I want to find an answer. I want to know what children think, feel, and know about plants when they are in the placed in their indoor play spaces. There is a lot of information on how children enjoy nature outside, but I want to know how children enjoy nature inside. A research study is something I am doing to try and find out answers to my question.

\section{YOUR CHOICE:}

You don't have to answer any questions if you don't want to, and you can leave at any time.

\section{WHAT ARE WE DOING RIGHT NOW?}

Right now I want to find out how you think we should set up plants in the classroom. We will pass this ball around and when it is your turn with the ball you can share your answers.

\section{GUIDING QUESTIONS:}

1. What do you like about plants?

2. What kind of plants do you like?

3. How do you play with plants?

4. Where should we put the plants in the classroom? 


\section{APPENDIX G Interview Guide Can Ecological Relationships be Grown Indoors?}

The interviews within this research are informal and field observation based. These interviews may be individual or with groups of up to four children.

\section{OBSERVATION BASED}

While spending time observing the classroom, the researcher may feel there are actions that need further explanations from the children. The need for specific interviews will be guided by the following actions.

- Children discussing the plants.

- Children touching or interacting with the plants.

- Children who seem to avoid the plants.

\section{ASSENT:}

Before asking questions the research will ask for assent.

1. Would you like to answer some questions about the plants for my research project? If you don't want to you can say no, shake your head, walk away or just not answer.

2. May I audio-record you so I get your answer right?

\section{GUIDING QUESTIONS}

Based on the observations the researcher may ask interview questions based on the following questions:

1. Why did you do that with the plant?

2. How do you feel about the plant?

3. What do you think about the plant?

4. What do you know about the plant? 


\section{APPENDIX $\mathrm{H}$ \\ Interview During Narrative Guide Can Ecological Relationships be Grown Indoors?}

During the second week of data collection, children will be invited to individually share narratives on the plants.

Children will be asked if they would like to create art, make up a story, or share their ideas in their own chosen way. If the child does not have a specific way they would like to share their ideas, the researcher will suggest art or storytelling.

Assent will be gained first and a discussion about the narrative will follow during or after the activity using the guiding questions.

\section{ASSENT:}

Before participating in narratives the research will ask for assent.

3. Would you like to share your ideas about what you know and think about the plants using art, or by telling me story, or in any other way for my research project? If you don't want to you can say no, shake your head, walk away or just not answer.

4. May I audio-record you so I get your story right?

5. How would you like to share your ideas?

\section{GUIDING QUESTIONS}

Based on the child's chosen narrative, the researcher will clarify children's ideas using the following guide of questions. For example, if the child has chosen to create art, questions may be asked during and after the creation process. If the child has chosen to create a story, questions will be asked after the completion of the story.

1. Can you tell me about this part of your creation?

2. Why did you add this to your creation?

3. What does this part of your creation mean?

4. What does this tell me about the plants? 


\section{REFERENCES}

Adair, J. K., \& Doucet, F. (2014). The impact of race and culture on play in early childhood classrooms. In L. Brooker, M. Blaise, \& S. Edwards (Eds.), The Sage handbook of play and learning in early childhood (pp. 345-365). London: Sage.

Adams, S., \& Savahl, S. (2017). Nature as children's space: A systematic review. The Journal of Environmental Education, 48(5), 291-321. doi:10.1080/00958964.2017.1366160

Angrosino, M. (2007). Data collection in the field. In Qualitative research kit: Doing ethnographic and observational research (pp. 35-52). London: SAGE Publications Ltd. doi: $10.4135 / 9781849208932$

Baudrillard, J. (1988). Simulacra and simulations. In J. Baudrillard, \& M. Poster (Ed.), Selected Writings (pp. 166-184). Stanford: Stanford University Press. Retrieved from https://pdfs.semanticscholar.org/3c0c/cbb2850ab4cd248bbb8c93161d3865869cc0.pdf

Blaise, M., Hamm, C., \& Iorio, J. (2017). Modest witness(ing) and lively stories: paying attention to matters of concern in early childhood. Pedagogy, Culture \& Society, 25(1), 31-41. doi:http://dx.doi.org/10.1080/14681366.2016.1208265

Braidotti, R. (2013). Yes, there is no crisis. Working towards the posthumanities. International Journal for History, Culture and Modernity, 1(2), 187-199. doi:http://doi.org/10.18352/hcm.412

Braidotti, R. (2018). A theoretical framework for the critical posthumanitites. Theory, Culture \& Society, O(0), 1-31. doi:10.1177/0263276418771486

Burman, E. (1994). Origins. In Deconstructing Developmental Psychology (pp. 9-22). New York, NY: Routledge. 
Cherryholmes, C. (1988). Power and criticism: Poststructuralism investigations in education. New York, NY: Teachers College Press.

Chawla, L. (2007). Childhood experiences associated with care for the natural world: A theoretical framework for empirical results. Children Youth and Environments, 17(4), 144-170

Cole, P. (2002). land and language: translating aboriginal cultures. Canadian Journal of Environmental Education, 7(1), 67-85.

Cole, P. (2018, Sept. 17). Email

Cole, P. (2018, Oct. 1). Email

Creswell, J. (2008). Ethnographic Design. In Educational research: Planning, conducting, and evaluating quantitative and qualitative research (3rd ed., pp. 472-510). United States of America: Pearson Education, Inc.

Creswell, J. (2014). Research design: Qualitative, quantitative, and mixed methods approaches. Thousand Oaks, CA: SAGE Publications, Inc.

Dahlberg, G. \& Moss, P. (2018). Reconceptualizing evaluation in early childhood education. In M. Bloch, B. Swadener, \& G. Cannella (Eds.), Reconceptualizing early childhood education and care - A READER (Second ed., pp. 93-112). New York, NY: Peter Lang Publishing, Inc

David, M., Edwards, R., \& Alldred, P. (2001). Children and school-based research: 'Informed consent' or 'educated consent'? British Education Research Journal, 27(3), 347-365. doi:10.1080/01411920120048340 
Deloria, V. (2001). American Indian Metaphysics. In V. Deloria, \& D. Wildcat, Power and place: Indian education in America (pp. 1-6). Goldon, Colorado: Fulcrum Resources. Retrieved from https://nycstandswithstandingrock.files.wordpress.com/2016/10/vinedeloria-jr-daniel-r-wildcat-power-and-place-indian-education-in-america.pdf

Government of Canada. (2014). The city/suburb contrast: How can we measure it? Retrieved from Statistics Canada: https://www150.statcan.gc.ca/n1/pub/11-008$\underline{\text { x/2008001/article/10459-eng.htm }}$

Hamilton, L., \& Taylor, N. (2017). Ethnography after humanism: Power, politics and method in multi-species research. Palgrave Macmillan Limited. doi:10.1057/978-1-137-53933-5

Heydon, R. \& Davies, E. (2019). Intergenerationaling: Children, elders and materials making waves. In B. Hodgins (Ed.), Feminist research fo 21st-century childhoods (pp. 53-62). London: Bloomsbury Academic.

Hordyk, S., Dulude, M., \& Shem, M. (2015). When nature nurtures children: Nature as a containing and holding space. Children's Geographies, 13(5), 571-588. . doi:10.1080/14733285.2014.923814

Intergovernmental Panel on Climate Change. (2018). Special Report: Global Warming of $1.5^{\circ}$ C. Intergovernmental Panel on Climate Change. Retrieved from https://www.ipcc.ch/sr15/

Joseph, B. (2018). 21 things you may not know about the Indian Act. Port Coquitlam, BC: Indigenous Relations Press.

Kalvaitis, D., \& Monhardt, R. (2012). The architecture of children's relationships with nature: A phenomenographic investigation seen through drawings and written narratives of 
elementary students. Environmental Education Research, 18(2), 209-227.

doi:10.1080/13504622.2011.598227

Kharkhordin, O. (2001). Nation, nature and natality: New dimensions of political action. European Journal of Social Theory, 4(4), 459-478. doi:https://doi.org/10.1177/13684310122225262

Kimmerer, R. (2013). Braiding sweetgrass: Indigenous wisdom, scientific knowledge, and the teachings of plants. Minneapolis, Minnesota: Milkweed Editions.

Kristofferson, K. W. (2014). The nature of slacktivism: How the social observability of an initial act of token support affects subsequent prosocial action. Journal of Consumer Research, 40(6), 1149-1166. doi:10.1086/674137

Kummen, K. (2019). Crowing: Coevolving relationships. In B. Hodgins (Ed.), Feminist research for 21st-century childhoods (pp. 85-92). London: Bloomsbury Academic.

Leavy, P. (2017). Research design: Quantitative, qualitative, mixed methods, arts-based, and community-based partcipatory research approaches. New York, NY: The Guilford Press.

Levine, R. (2007). Ethnographic studies of childhood: A historical overview. American Anthropologist, 109(2), 247-260. doi:10.1525/aa.2007.109.2.247

Lewis-Beck, M., Bryman, A., \& Futing Liao, T. (2004). The SAGE encyclopedia of social science research methods. Thousand Oaks, CA: Sage Publications, Inc. doi:10.4135/9781412950589

Lincoln, Y., \& Guba, E. (2009). The only generalization is: there is no generalization. In R. Gomm, M. Hammersley, \& P. Foster, Case study method (pp. 27-44). London: SAGE Publications Ltd. doi:10.4135/9780857024367 
McLuhan, M. (2013). The gadget lover: Narcissus as narcosis. In Understanding media: The extensions of man (pp. 36-40). Berkley, CA: Gingko Press.

Mendell, M., \& Heath, G. (2005). Do indoor pollutants and thermal conditions in schools influence student performance? A critical review of the literature. Indoor Air, 15(1), 2752. doi:10.1111/j.1600-0668.2004.00320.x

Myers, N. (2016). Photosynthesis. Retrieved from Society for cultural antrhopology: https://culanth.org/fieldsights/photosynthesis

Myers, N. (2017a). Becoming sensor in sentient worlds: A more-than-natural history of a black oak savannah. (G. Bakke, \& M. Peterson, Eds.) Between matter and method: Encounters in anthropology and art, 73-96. Retrieved from https://www.academia.edu/35078080/Becoming_Sensor_in_Sentient_Worlds_A_More-thannatural_History_of_a_Black_Oak_Savannah_in_Between_Matter_and_Method_edited_b y_Gretchen_Bakke_and_Marina_Peterson

Myers, N. (2017b). From the anthropocene to the planthroposcene: Designing gardens for plant/people involution. History and Anthropology, 28(3), 297-301. doi:https://doi.org/10.1080/02757206.2017.1289934

Myers, N. (2019). From edenic apocalypse to gardens against eden: Plants and people in and after the Anthropocene. In K. Hetherington (Ed.), Infrastructure, Environment, and Life in the Anthropocene (pp. 115-148). USA: Duke University Press Books. Retrieved from https://www.academia.edu/38607269/From_Edenic_Apocalypse_to_Gardens_Against_E den_Plants_and_People_in_and_After_the_Anthropocene?email_work_card=title 
Murris, K. \& Borchers, C. (2019). Childing: A different sense of time. In B. Hodgins (Ed.), Feminist research fo 21 st-century childhoods (pp. 197-208). London: Bloomsbury Academic.

Nelson, N. (2019). Tracking: Cultivating the "arts of awareness" in early childhood. In B. Hodgins (Ed.), Feminist research fo 21st-century childhoods (pp. 101-110). London: Bloomsbury Academic.

Nelson, N., Pacini-Ketchabaw, P., \& Nxumalo, F. (2018). Rethinking nature-based approaches in early childhood education: Common worlding practices. Journal of Childhood Studies, 43(1), 4-14. doi:10.18357/jcs.v43i1.18261

Newberry, L. (2012). Canoe pedagogy and colonial history: Exploring contested spaces of outdoor environmental education. Canadian Journal of Environmental Education, 17, 3045. Retrieved from https://cjee.lakeheadu.ca/article/view/1112

Nxumalo, F. (2018). Situating Indigenous and Black childhoods in the Anthropocene. In A. Cutter-Mackenzie, K. Malone, \& E. Barratt Hacking (Eds.), Research Handbook on Childhoodnature (pp. 1-22). Springer International Handbooks of Education. doi:https://doi.org/10.1007/978-3-319-51949-4_37-2

Nxumalo, F. (2019). Presencing: Decolonial attunements to children's place relations. In B. Hodgins (Ed.), Feminist research fo 21 st-century childhoods (pp. 159-167). London: Bloomsbury Academic.

Nxumalo, F., \& ross, m. (2019). Envisioning Black space in environmental education for young children. Race Ethnicity and Education, 22(4), 502-524. doi:10.1080/13613324.2019.1592837 
O'Reilly, K. (2009). Sage key Concepts: Key concepts in ethnography. London: SAGE Publications Ltd. doi:10.4135/9781446268308

Osgood, J. (2016). Postmodernist theorising in ECEC: making the familiar strange in pursuit of social justice. In T. David, K. Goouch, \& S. Powell (Eds.), Routledge handbook of philosophies and theories of early childhood education and care (pp. 157-164). New York, NY: Routledge.

Oulton, K., Gibson, F., Sell, D., Williams, A., Pratt, L., \& Wray, J. (2016). Assent for children's participation in research: Why it matters and making it meaningful. Child: Care, Health and Development, 42(4), 588-597. doi:10.1111/cch.12344

Pacini-Ketchabaw, V. \& Boucer, K. (2019). Claying: Attending to Earth's caring relations. In B. Hodgins (Ed.), Feminist research fo 21st-century childhoods (pp. 25-24). London: Bloomsbury Academic.

Pacini-Ketchabaw, V., \& Nxumalo, F. (2015). Unruly raccoons and troubled educators: Nature/Culture divides in a childcare centre. Environmental Humanities, 7(1), 151-168. doi:10.1215/22011919-3616380

Pacini-Ketchabaw, V., \& Nxumalo, F. (2018). Posthumanist imaginaries for decolonizing early childhood praxis. In M. Bloch, B. Swadener, \& G. Cannella (Eds.), Reconceptualizing early childhood education and care - A READER (2nd ed., pp. 215-228). New York, NY: Peter Lang Publishing, Inc.

Pacini-Ketchabaw, V., Taylor, A., \& Blaise, M. (2016). De-centring the human in multispecies ethnographies. In C. Taylor, \& C. Hughes (Eds.), Posthuman Research (pp. 149-167). Hampshire: Palgrave Macmillan. 
Peters, M., \& Burbules, N. (2004). Postructuralsim and educational research. United States of America: Rowman \& Littlefield Publishers, Inc.

Pulido, L. (2017). Geographies of race and ehtnicity II: Enviornmental racism, racial capitalism and state-sanctioned violence. Progress in Human Geographies, 41(4), 524-533. doi:10.1177/0309132516646495

Rautio, P. (2017). Thinking about life and species lines with Pietari and Otto (and garlic breath). TRACE: Finnish Journal for Human-Animal Studies, 3, 94-102. Retrieved from https://trace.journal.fi/article/view/63310

Rautio, P., \& Jokinen, P. (2015). Children's relations to the more-than-human-world beyond developmental views. In B. Evans, J. Horton, \& T. Skelton (Eds.), Play, Recreation, Health and Wellbeing - Geographies of Children and Young People 9 (pp. 1-15). Singapore: Springer. doi:10.1007/978-981-4585-96-5_2-1

Riain, S. (2009). Extending the ethnographic case study . In D. Byrne, \& C. C. Ragin (Eds.), The SAGE handbook of case-based methods (pp. 289-306). London: SAGE Publications Ltd. doi:10.4135/9781446249413

Rice, C., \& Torquati, J. (2013). Assessing connections between young children's affinity for nature and their experiences in natural outdoor settings in preschools. Children Youth and Environments, 23(2), 78-102. doi:10.7721/chilyoutenvi.23.2.0078

Rousseau, J.J. (1896/2003). Book first. Infancy - general principles. In Émile (Trans. W. H. Payne). (pp. 1-40). Amherst, NY: Prometheus. 
Schinz, A. (1929). The concept of nature in philosophy and literature; a consideration of recent discussions. Proceedings of the American Philosophical Society, 68(3), 207-225. Retrieved from http://www.jstor.org/stable/984209

Shillington, L., \& Murnaghan, A. (2016). Urban political ecologies and children's geographies: Queering urban ecologies of childhood. International Journal of Urban and Regional Research, 40(5), 1017-1035. doi:10.1111/1468-2427.12339

Stake, R. (2009). The case study method in social inquiry. In R. Gomm, M. Hammersley, \& P. Foster (Eds.), Case study method (pp. 18-26). London: SAGE Publications Ltd. doi:10.4135/9780857024367

Soga, M., Gaston, K., Yamaura, Y., Kurisu, K., \& Hanaki, K. (2016). Both direct and vicarious experiences of nature affect children's willingness to conserve biodiversity. International Journal of Environmental Research and Public Health, 13(6), 1-12. doi:10.3390/ijerph13060529

Sundberg, J. (2014). Decolonizing posthumanist geographies. Cultural Geographies, 21(1), 3347. doi:10.1177/1474474013486067

TallBear, K. (2011). Why Interspecies Thinking Needs Indigenous Standpoints. Fieldsights. Retrieved from https://culanth.org/fieldsights/why-interspecies-thinking-needsindigenous-standpoints

Taylor, A. (2017). Beyond stewardship: common world pedagogies for the Anthroprocene. Environmental Education Research, 20(10), 1448-1461. doi:https://doi.org/10.1080/13504622.2017.1325452 
Taylor, A. (2018). Engaging with the conceptual tools and challenges of poststructural theories. In M. Fleer, \& B. van Oers (Eds.), International handbook of early childhood education (pp. 91-115). New York, NY: Springer.

Taylor, A. (2019). Rabbiting: Troubling the legacies of invasion. In B. Hodgins (Ed.), Feminist research fo 21st-century childhoods (pp. 111-120). London: Bloomsbury Academic.

Taylor, A., \& Giugni, M. (2012). Common worlds: Reconceptualizing inclusion in early childhood communities. Contemporary Issues in Early Childhood, 13(2), 108-119. doi:http://dx.doi.org/10.2304/ciec.2012.13.2.108

Tesar, M., \& Arndt, S. (2018). Posthuman childhoods: Questions concerning 'quality'. In M. Bloch, B. Swadener, \& G. Cannella (Eds.), Reconceptualizing early childhood education and care - A READER (2nd ed., pp. 112-128). New York, NY: Peter Lang Publishing, Inc.

Tsing, A. (2013). More-than-human sociality: A call for critical description. In K. Hastrup (Ed.), Antrhopology and Nature (pp. 27-42). New York, NY: Routledge.

University of Alberta [Anthropocene, Ecology, Pedagogy: The Future in Question]. (2015, Dec. 15). Joshua LaBare \& Kim TallBear matters of life and death [Video file]. Retrieved from https://www.youtube.com/watch?v=tjiVcwpBhSc

Urban, M. (2018). Learning from the margins: Early childhood imaginaries, "normal science," and the case for a radical reconceptualization of research and practice. In M. Bloch, B. Swadener, \& G. Cannella (Eds.), Reconceptualizing early childhood education and care A READER (Second ed., pp. 273-288). New York, NY: Peter Lang Publishing, Inc 
van Dooren, T., \& Rose, D. B. (2016). Lively ethography: Storying animist worlds.

Environmental Humanities, 8(1), 77-94. doi:10.1215/22011919-3527731

von Benzon, N. (2018). Discussing nature, 'doing' nature: For an emancipatory approach to conceptualizing young people's access to outdoor green space. Geoforum, 93, 79-86. doi:10.1016/j.geoforum.2018.05.004

Wells, N., \& Lekies, K. (2006). Nature and the life course: Pathways from childhood nature experiences to adult environmentalism. Children Youth and Environments, 16(1), 1-24. Retrieved from http://www.jstor.org/stable/10.7721/chilyoutenvi.16.1.0001

Whyte, K. (2018). Indigenous science (fiction) for the Anthropocene: Ancestral dystopias and fantasies of climate change crisis. Environment and Planning E: Nature and Space, 1(12), 224-242. doi:https://doi.org/10.1177/2514848618777621

Wolfe, C. (2010). Meaning and event; or, systems theory and "the reconstruction of destruction". In What is Posthumanism? (pp. 3-29). University of Minnesota Press. 